\title{
Rapid Crystallization and Kinetic Freezing of Site-Disorder in the Lithium Superionic Argyrodite Li6PS5Br
}

\author{
Ajay Gautam, Marcel Sadowski, Nils Prinz, Henrik Eickhoff, Nicolo Minafra, Michael Ghidiu, Sean Culver, \\ Karsten Albe, Thomas Fässler, Mirijam Zobel, Wolfgang Zeier
}

Submitted date: 10/09/2019 - Posted date: 11/09/2019

Licence: CC BY-NC-ND 4.0

Citation information: Gautam, Ajay; Sadowski, Marcel; Prinz, Nils; Eickhoff, Henrik; Minafra, Nicolo; Ghidiu, Michael; et al. (2019): Rapid Crystallization and Kinetic Freezing of Site-Disorder in the Lithium Superionic Argyrodite Li6PS5Br. ChemRxiv. Preprint.

Lithium argyrodite superionic conductors are currently being investigated as solid electrolytes for all-solid-state batteries. Recently, in the lithium argyrodite $\mathrm{Li}_{6} \mathrm{PS}_{5} \mathrm{X}(\mathrm{X}=\mathrm{Cl}, \mathrm{Br}, \mathrm{I})$, a site-disorder between the anions $S^{2-}$ and $X^{-}$has been observed, which strongly affects the ionic transport and appears to be a function of the halide present. In this work, we show how such disorder in $\mathrm{Li}_{6} \mathrm{PS}_{5} \mathrm{Br}$ can be engineered viathe synthesis method. By comparing fast cooling (i.e. quenching) to more slowly cooled samples, we find that anion site-disorder is higher at elevated temperatures, and that fast cooling can be used to kinetically trap the desired disorder, leading to higher ionic conductivities as shown by impedance spectroscopy in combination with ab-initiomolecular dynamics. Furthermore, we observe that after milling, a crystalline lithium argyrodite can be obtained within one minute of heat treatment. This rapid crystallization highlights the reactive nature of mechanical milling and shows that long reaction times with high energy consumption are not needed in this class of materials. The fact that site-disorder induced viaquenching is beneficial for ionic transport provides an additional approach for the optimization and design of lithium superionic conductors.

File list (2)

Manuscript.pdf (17.00 MiB)

view on ChemRxiv • download file

Supporting Information.pdf (10.00 MiB)

view on ChemRxiv - download file 


\title{
Rapid crystallization and kinetic freezing of site-disorder in the lithium superionic argyrodite $\mathrm{Li}_{6} \mathrm{PS}_{5} \mathrm{Br}$
}

\author{
Ajay Gautam ${ }^{\mathrm{a}, \mathrm{b}}$, Marcel Sadowski ${ }^{\mathrm{c}}$, Nils Prinz ${ }^{\mathrm{d}}$, Henrik Eickhoff ${ }^{\mathrm{e}}$, Nicolò Minafra ${ }^{\mathrm{a}, \mathrm{b}}$, Michael \\ Ghidiu $^{\mathrm{a}, \mathrm{b}}$, Sean P. Culver ${ }^{\mathrm{a}, \mathrm{b}}$, Karsten Albe ${ }^{\mathrm{c}}$, Thomas F. Fässler,e, Mirjam Zobel ${ }^{\mathrm{d}}$, Wolfgang G. \\ Zeier*a,b \\ ${ }^{a}$ Institute of Physical Chemistry, Justus-Liebig-University Giessen, Heinrich-Buff-Ring \\ 17, D-35392 Giessen, Germany. \\ ${ }^{b}$ Center for Materials Research (LaMa), Justus-Liebig-University Giessen, Heinrich-Buff- \\ Ring 16, D-35392 Giessen, Germany. \\ ${ }^{c}$ Department of Materials Science, Technische Universität Darmstadt, Otto-Berndt- \\ Strasse 3, D-64287 Darmstadt, Germany. \\ ${ }^{d}$ Department of Chemistry, University of Bayreuth, Universitätsstrasse 30, D-95440 \\ Bayreuth, Germany. \\ ${ }^{e}$ Department of Chemistry, Technische Universität München, Lichtenbergstrasse 4, D-85747 \\ Garching bei München, Germany.
}

\begin{abstract}
Lithium argyrodite superionic conductors are currently being investigated as solid electrolytes for all-solid-state batteries. Recently, in the lithium argyrodite $\mathrm{Li}_{6} \mathrm{PS}_{5} \mathrm{X}(\mathrm{X}=\mathrm{Cl}, \mathrm{Br}, \mathrm{I})$, a sitedisorder between the anions $\mathrm{S}^{2-}$ and $\mathrm{X}^{-}$has been observed, which strongly affects the ionic transport and appears to be a function of the halide present. In this work, we show how such disorder in $\mathrm{Li}_{6} \mathrm{PSS}_{5} \mathrm{Br}$ can be engineered via the synthesis method. By comparing fast cooling (i.e. quenching) to more slowly cooled samples, we find that anion site-disorder is higher at elevated temperatures, and that fast cooling can be used to kinetically trap the desired disorder, leading to higher ionic conductivities as shown by impedance spectroscopy in combination with ab-initio molecular dynamics. Furthermore, we observe that after milling, a crystalline lithium argyrodite can be obtained within one minute of heat treatment. This rapid crystallization highlights the reactive nature of mechanical milling and shows that long reaction times with high energy consumption are not needed in this class of materials. The fact that site-disorder induced via quenching is beneficial for ionic transport provides an additional approach for the optimization and design of lithium superionic conductors.
\end{abstract}




\section{Introduction}

Solid-state batteries show great promise as an alternative to liquid electrolyte-based lithium-ion batteries. $^{1-4}$ Primarily, all-solid-state batteries that utilize lithium thiophosphates exhibit remarkable properties, making them a strong competitor to the current lithium-ion technology. ${ }^{3-}$ ${ }^{9}$ Materials such as $\mathrm{Li}_{10} \mathrm{GeP}_{2} \mathrm{~S}_{12}$ and the many substitutions therein, ${ }^{3,10-15} \mathrm{Li}_{2} \mathrm{~S}-\mathrm{P}_{2} \mathrm{~S}_{5}$ glasses, ${ }^{16-}$ 18 as well as $\mathrm{Li}_{6} \mathrm{PS}_{5} \mathrm{X}$ argyrodites with $\mathrm{X}=\mathrm{Cl}, \mathrm{Br}, \mathrm{I}^{4,5,19-25}$ exhibit high ionic conductivities which, coupled with the mechanically soft nature of these materials, makes this class of lithium thiophosphates quite promising. Nevertheless, many key fundamental processes governing the properties of these materials remain shrouded by ambiguity, e.g. the underlying influence of the employed synthetic approach on the resultant structure is still unclear and subtler structural changes on the local scale, such as lattice defects as well as structural and site-disorder, have a strong influence on the ionic transport as well. 5,19,26,27

(a)

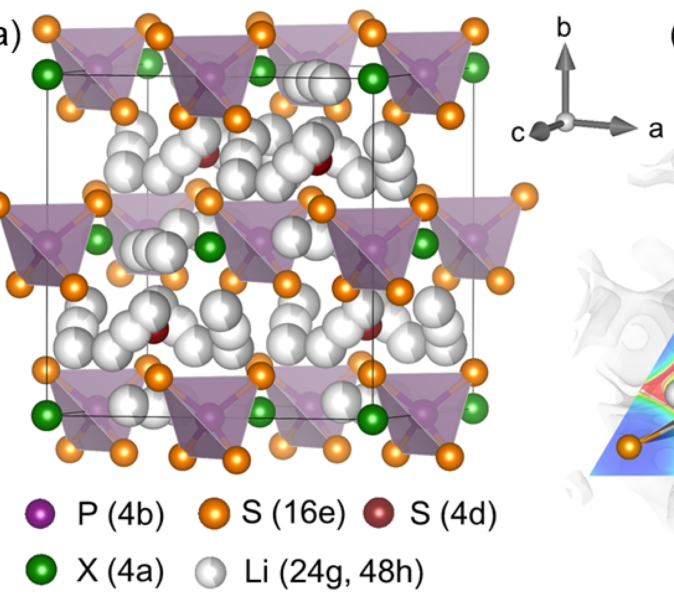

$x(4 a)-\operatorname{Li}(24 \mathrm{~g}, 48 \mathrm{~h})$ (b)

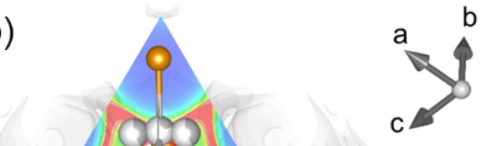

ono

$0-8-60$

\section{.}

Figure 1: (a) Crystal structure of $\mathrm{Li}_{6} \mathrm{PS}_{5} B r^{19}$ without any site-disorder between the positions $4 a$ and $4 d$. (b) Calculated bond valence sum ${ }^{21}$ showing that the long-range jump between the $\mathrm{Li}^{+}$cages represents the bottleneck for diffusion.

Among the lithium thiophosphates, recent interest has been paid especially to the argyrodites due to their seemingly intrinsic anionic site-disorder and its associated influences on transport properties. ${ }^{19,28}$ The crystal structure of $\mathrm{Li}_{6} \mathrm{PS}_{5} \mathrm{X}$ is shown in Figure 1 along with a bond valence sum as calculated by Minafra et al. ${ }^{21}$ In the absence of site-disorder, the halide anions $\mathrm{X}^{-}$ arrange in a face-centered cubic lattice (Wyckoff $4 a$ ) with the ortho-thiophosphate $\mathrm{PS}_{4}{ }^{3-}$ tetrahedra on the octahedral sites ( $\mathrm{P}$ on Wyckoff $4 b$ ) and the free $\mathrm{S}^{2-}$ in half of the tetrahedral sites (Wyckoff $4 d$ ). There are two distinct $\mathrm{Li}^{+}$positions, namely the $48 h$ and $24 g$ Wyckoff positions, which form $\mathrm{Li}^{+}$cages around the free $\mathrm{S}^{2-}$ on Wyckoff $4 d$, resulting in three different jump processes: a doublet jump $(48 h-24 g-48 h)$, an intra-cage jump $(48 h-48 h)$ and the inter- 
cage jump ( $48 h-48 h$ between the individual $\mathrm{Li}^{+}$cages). Recent work has shown that for $\mathrm{X}=$ $\mathrm{Cl}$ and $\mathrm{Br}$, significant site-disorder exists between the $\mathrm{X}^{-}$and $\mathrm{S}^{2-}$ anions, which directly affects the bottleneck of diffusion from one cage to another, i.e. the inter-cage jump (as visually shown by the bond valence sum in Figure 1). ${ }^{19,22,28,29}$ In contrast, for $\mathrm{Li}_{6} \mathrm{PS}_{5} \mathrm{I}$, no site-disorder occurs due to the large size mismatch between $\mathrm{S}^{2-}$ and $\mathrm{I}^{-} \cdot{ }^{19}$ This site-disorder can be chemically influenced by aliovalent substitution, for instance in $\mathrm{Li}_{6+{ }_{x}} \mathrm{P}_{1-x} \mathrm{M}_{x} \mathrm{~S}_{5} \mathrm{I}$ (with $\mathrm{M}=\mathrm{Si}, \mathrm{Ge}$ ), ${ }^{5,30}$ as well as by increasing the halide content in $\mathrm{Li}_{6-x} \mathrm{PS}_{5-x} \mathrm{Cl}_{1+x},{ }^{25}$ both of which improve the ionic conductivity. However, while these chemical approaches affect the site-disorder, possible influences of the synthesis conditions or heat treatment on the kinetics of the site-disorder have not yet been explored.

In this study, inspired by the open question of how crystallization kinetics affect the sitedisorder in the lithium argyrodites, we investigate the influence of the synthesis procedure on the structure and ionic transport of $\mathrm{Li}_{6} \mathrm{PS}_{5} \mathrm{Br}$. First, an argyrodite precursor is prepared via mechanochemical technique, which is then subjected to different heating protocols in order to monitor the dependence of the site-disorder on the crystallization time and cooling rate. Importantly, the mechanically alloyed precursor mixture is either quenched from hightemperature or allowed to cool more slowly to enable additional ordering. Using a combination of Rietveld refinements against X-ray diffraction data, pair distribution function analysis and Raman spectroscopy, we find that during rapid-quenching a higher site-disorder can be kinetically trapped and rapid crystallization can occur within one minute of reaction time. Further, the kinetic trapping of the site-disorder leads to an increase in the ionic conductivity as determined by electrochemical impedance spectroscopy and ab-initio molecular dynamics simulations. This work demonstrates that site-disorder can be kinetically controlled by tuning the synthesis conditions, that rapid crystallization is possible in the lithium argyrodites, and that the synthetic protocol strongly affects the structure and transport properties in lithium thiophosphate superionic conductors.

\section{Experimental Section}

Synthesis of milled precursor. All handling of solids was performed in an Ar-filled glovebox to prevent exposure to oxygen and water. $\mathrm{Li}_{6} \mathrm{PS}_{5} \mathrm{Br}$ was synthesized using ball milling. The starting materials of lithium sulfide ( $\mathrm{Li}_{2} \mathrm{~S}$, Alfa-Aesar, $\left.99.9 \%\right)$, phosphorus pentasulfide $\left(\mathrm{P}_{4} \mathrm{~S}_{10}\right.$, Merck, $99 \%$ ), and lithium bromide (LiBr, ultradry, Alfa-Aesar, $99.99 \%$ ) were mixed in the stoichiometric ratio and hand-ground in an agate mortar for 5 min to obtain an initial uniform mixing. The obtained mixture (3g) was then ball milled (Fritsch Pulveristette 7 premium line) 
at $510 \mathrm{rpm}$ using a $\mathrm{ZrO}_{2}$ milling set (45 $\mathrm{mL}$ bowl with $120 \mathrm{~g}$ of $5 \mathrm{~mm}$ diameter milling balls). The milling was performed for 50 hours with intermediate cooling time (every 10 min for 10 min) to prevent excessive heating of the obtained materials. During the process, the grinding vessel was opened twice to hand grind the materials to obtain a uniform precursor and remove sample stuck to the walls of the vials. The obtained precursor was pressed into a pellet and then filled into quartz ampoules (10 $\mathrm{mm}$ inner diameter and 8-10 $\mathrm{cm}$ in length). Prior to the filling, the quartz ampoules were carbon coated and preheated at $1073 \mathrm{~K}$ under dynamic vacuum to remove the all trace of water in the reaction atmosphere. The quartz ampoules were sealed under vacuum.

Temperature treatment experiments. The sealed quartz ampoules were inserted into a tube furnace (Nabertherm) that was already equilibrated at the reaction temperature of $823 \mathrm{~K}$ and were allowed to react for specific periods of time: $1 \mathrm{~min}, 5 \mathrm{~min}, 30 \mathrm{~min}$ and 5 hours. Once the reaction time was completed, two different cooling techniques were used: (1) quenching in liquid nitrogen for rapid cooling ("quenching") and (2) naturally cooling after shutting off the furnace without removing the insulating plug in the tube end ("standard cooling"). An additional test was performed in which the furnace was kept at $823 \mathrm{~K}$ for 30 min then a cooling rate of $4 \mathrm{~K} / \mathrm{h}$ over 5 days ("slow cooling") was applied. The resulting samples were handground into a powder for diffraction studies and isostatically pressed into pellets for electrochemical measurements.

$X$-ray powder diffraction. X-ray diffraction measurements were carried out at room temperature to obtain the phase purities and relevant structural parameters with a STOE Stadi P diffractometer ( $\mathrm{Ge}(111)$ monochromator; $\mathrm{Cu} \mathrm{K} \alpha_{1}$ radiation, $\lambda=1.54056 \AA$ ) using a Dectris MYTHEN $1 \mathrm{~K}$ detector in Debye-Scherrer geometry. All samples were sealed in glass capillaries $(\varnothing=0.5 \mathrm{~mm})$ prior to measurement collection, which was carried out in the $2 \theta$ range of $10-90^{\circ}$.

Rietveld Analysis. The raw data were processed with the WinXPOW software package ${ }^{31}$ and Rietveld refinement was carried out using the TOPAS-Academic V6 software package. ${ }^{32}$ Fit indicator $-\mathrm{R}_{\mathrm{wp}}$, $\mathrm{R}_{\exp }$, and goodness-of-fit were used to assess the quality of the refined structural model. The following parameters were initially refined: (1) scale factor, (2) 10 coefficients for a Chebyshev function background, (3) peak shape, (4) lattice parameters, (5) zero error, (6) fractional atomic coordinates, (7) isotropic atomic displacement parameters. Finally, (8) atomic occupancies of the anions were then allowed to refine simultaneously with all other parameters to quantify the anion site-disorder. The Li atomic positions and occupancies were fixed to the 
values extracted from the neutron refinement of $\mathrm{Li}_{6} \mathrm{PS}_{5} \mathrm{Br}$ from Kraft et al. ${ }^{19}$ and the isotropic atomic displacement parameters for Li were fixed to $3 \AA^{2}$. The thermal displacement of the elements in the $\mathrm{PS}_{4}{ }^{3-}$ polyhedral unit, $\mathrm{P}$ and $\mathrm{S}$, were constrained as a rigid body.

Raman spectroscopy. Raman spectra of the samples were carried out using a Senterra Raman spectrometer (Bruker, excitation wavelength of $532 \mathrm{~nm}$ ). The spectral range from 55 to 1555 $\mathrm{cm}^{-1}$ was used with a $50 \mathrm{X}$ objective and a power of $0.2 \mathrm{~mW}$. The samples were placed on the glass substrate in the glovebox and sealed by a cover glass and silicone vacuum grease to prevent exposure to air.

Pair distribution function analysis. X-ray diffraction measurements for pair distribution function were carried out at room temperature with a STOE STADI P PDF Mythen2 4K diffractometer ( $\mathrm{Ge}(111)$ monochromator; $\mathrm{Ag} \mathrm{K} \alpha_{1}$ radiation, $\lambda=0.5594 \AA$ ) using four Dectris MYTHEN2 R 1K detector in Debye-Scherrer geometry. All samples were sealed in glass capillaries $(\varnothing=0.5 \mathrm{~mm})$ prior to measurement collection, which was carried out in the $\mathrm{Q}$ range of $0.3-20.5 \AA^{-1}$.

Electrochemical Impedance spectroscopy. Total conductivities were measured by AC impedance spectroscopy using pellets $\left(\sim 2.4 \mathrm{~mm}\right.$ thickness, $\sim 84 \%$ density, $\sim 0.694 \mathrm{~cm}^{2}$ electrode area) with vapor deposited gold layers, the as-synthesized powder was pelletized by isostatic pressing and gold layers of around $200 \mathrm{~nm}$ thickness were deposited on both sides. The obtained pellets were sealed under Ar atmosphere in pouch bags using aluminum as the current collector for the transport measurements. Electrochemical impedance spectroscopy (EIS) was conducted in the temperature range of $253 \mathrm{~K}$ to $333 \mathrm{~K}$ (Weiss Klimatechnik Climate Chamber) using a SP300 impedance analyzer (Biologic Science Instruments) at frequencies from $7 \mathrm{MHz}$ to 100 $\mathrm{mHz}$ with an amplitude of $10 \mathrm{mV}$.

Ab-initio molecular dynamics simulations. Density Functional Theory (DFT) calculations were executed using the Vienna Ab-initio Simulation Package (VASP) ${ }^{33-36}$ using the PBE exchangecorrelation functional. ${ }^{37,38}$ Projector augmented-wave pseudopotentials ${ }^{39,40}$ were used as provided by VASP (Li_sv 10Sep2004, P 06Sep2000, S 06Sep2000, Br 06Sep2000). In order to obtain starting structures for ab-initio molecular dynamics (AIMD) simulation the following procedure was employed. First, the ionic positions and cell parameters of the $\mathrm{Li}_{6} \mathrm{PS}_{5} \mathrm{Br}$ unit cell without $\mathrm{Br}^{-} / \mathrm{S}^{2-}$ site-disorder and all $\mathrm{Li}$ located on the $24 g$ sites were optimized using an energy cutoff for the plane-wave basis set of $600 \mathrm{eV}$ and a k-mesh of $3 \times 3 \times 3$. The energy convergence criterion for the self-consistent electronic relaxations were $10^{-7} \mathrm{eV}$ and the force criterion for the ionic and cell optimization was $10^{-2} \mathrm{eV} / \AA$. The obtained cell parameter $(\mathrm{a}=$ 
$10.2855 \AA$ ) was used to generate a $\sqrt{2} \times \sqrt{2} \times 2$ supercell. The supercell program ${ }^{41}$ was then used to generate various configurations with $25 \%$ and $50 \% \mathrm{Br}^{-} / \mathrm{S}^{2}$ site- disorder while still keeping only the $24 g$ sites occupied with $\mathrm{Li}^{+}$, for simplicity. Assuming ideal charges of $\mathrm{Li}^{+}$, $\mathrm{P}^{5+}, \mathrm{S}^{2-}$ and $\mathrm{Br}^{-}$and by employing the supercell program's ability to calculate of Coulomb energies, two (three) low energy structures, two (three) high energy structures and two (four) random structures were chosen as representative examples for $25 \%$ (50 \%) disorder. Subsequently, the ionic positions were optimized while keeping the simulation box fixed. It is important to note that during this step some $\mathrm{Li}^{+}$ions spontaneously changed from $24 g$ sites to $48 \mathrm{~h}$ sites, representing the known structural arrangement. The resulting ten disordered structures and the ordered structure were used as starting structures for AIMD simulations at $500,600,700,800,900$ and $1200 \mathrm{~K}$ carried out with integration time steps of $1 \mathrm{fs}$ and reduced convergence criteria for the self-consistent electronic relaxations of $10^{-5} \mathrm{eV}$. A NVT ensemble was considered using only the gamma-point and the default plane-wave energy cutoffs as specified in the pseudopotentials. Mean-square displacements (MSD) after 20 to 60 ps were evaluated after allowing 5 ps of equilibration time. Trajectories have been visualized with the Open Visualization Tool (OVITO). ${ }^{42}$

\section{Results and Discussion}

Influence of the reaction procedure on the structure. In order to investigate the influence of the synthetic procedure on the structure and site-disorder in $\mathrm{Li}_{6} \mathrm{PS}_{5} \mathrm{Br}$, two different synthetic approaches were used. First, the precursors of $\mathrm{Li}_{2} \mathrm{~S}, \mathrm{P}_{2} \mathrm{~S}_{5}$ and $\mathrm{LiBr}$ were subjected to mechanical alloying to achieve proper mixing of the elements and prepare a glassy material. After forming the glass phase, all samples were sealed in quartz ampoules and inserted into a tube furnace that was already equilibrated at the target temperature of $823 \mathrm{~K}$. Subsequently, the samples were kept in the furnace for a specific duration (i.e. 1 minute, 5 minutes, 30 minutes and 5 hours) and were then either allowed to naturally cool in the furnace (Figure 2a) or quenched in liquid nitrogen for rapid cooling (Figure 2b). Representative Rietveld refinements of the resulting products after a one-minute heat treatment, for the standard cool and quenched samples, are shown in Figure $2 \mathrm{a}$ and $2 \mathrm{~b}$, respectively. All samples subjected to the heating at $823 \mathrm{~K}$ led to crystalline products. All other diffraction patterns and the tabulated structural data from the Rietveld refinements can be found in the Supporting Information (Figure S1-S7, Table S1-S9). 

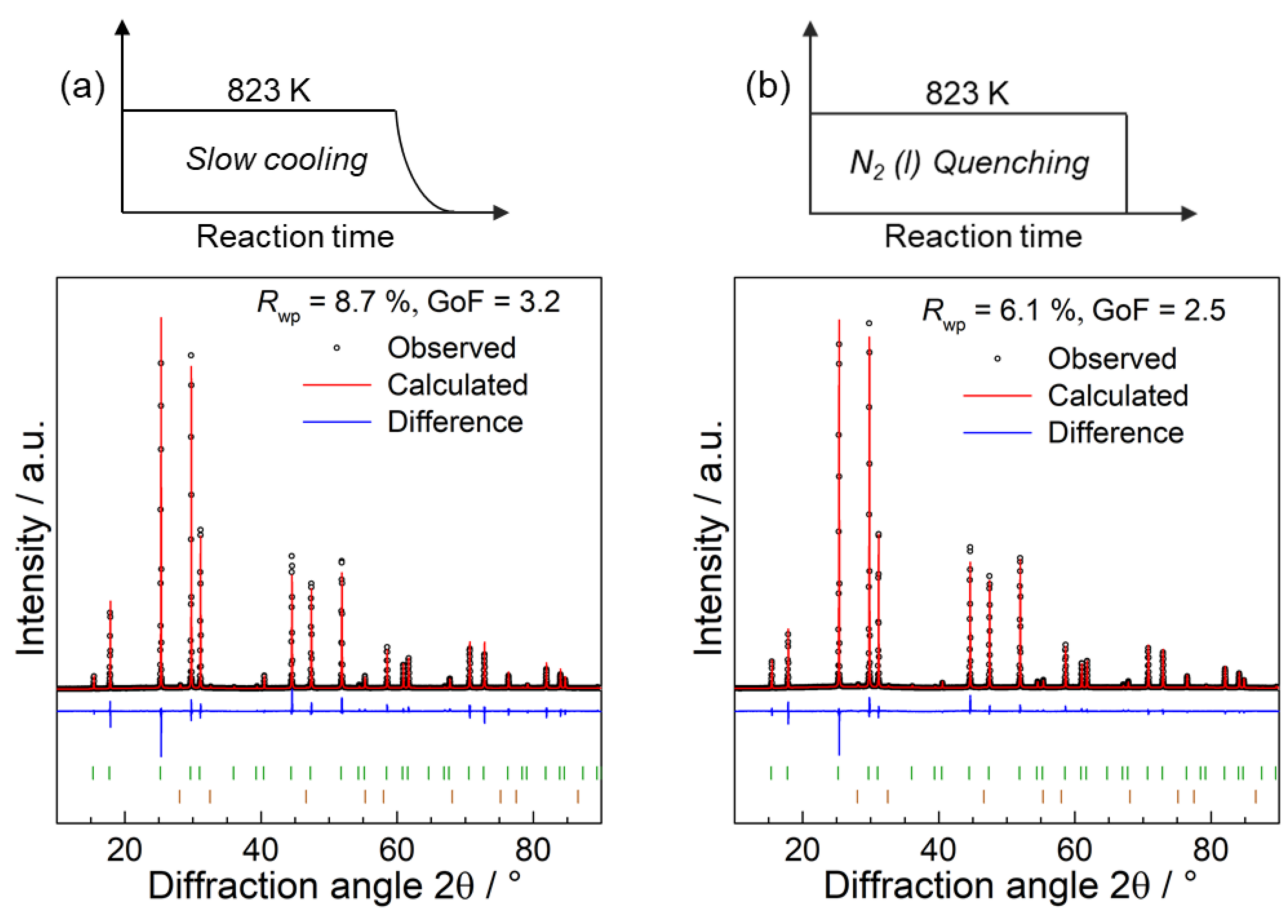

Figure 2: The ball-milled $\mathrm{Li}_{6} \mathrm{PS} 5 \mathrm{Br}$ precursor is vacuum sealed in a quartz ampoule and inserted into a furnace at $823 \mathrm{~K}$. After a certain crystallization time, the products are either (a) standard cooled or (b) quenched in a reservoir of liquid nitrogen. (Top) Schematics illustrating the different crystallization methods employed. (Bottom) Representative Rietveld refinements of laboratory X-ray diffraction data for the obtained (left) standard cooled and (right) liquid nitrogen quenched $\mathrm{Li}_{6} \mathrm{PS} \mathrm{S}_{5} \mathrm{Br}$ products after one minute of reaction time. Experimental data are shown in black and the red line denotes the calculated pattern, while the difference profile is shown in blue. Calculated positions of the $\mathrm{Li}_{6} \mathrm{PS}_{5} \mathrm{Br}$ and $\mathrm{LiBr}(\sim 0.73$ wt.\%) Bragg reflections are shown as green and dark orange vertical ticks, respectively.

It can be seen that already after one minute of reaction time, followed by quenching, a crystalline argyrodite can be obtained. The structural analyses, showing the refined lattice parameters of all samples as well as the change in the site-disorder between the $\mathrm{Br}^{-}$and $\mathrm{S}^{2-}$ anions (the population of $\mathrm{Br}^{-}$ions moving from Wyckoff $4 a$ to $4 d$ ), can be seen in Figure 3 . Notably, quenching leads to a systematically lower lattice parameter relative to the standard cooling procedure. Further, different cooling routines may result in strain and changes in particle sizes. A Williamson-Hall plot can be found in the Supporting Information Figure S9, which shows that the cooling rate has no detectable influence on the materials microstructure. In addition, consistent throughout the series, the more rapid cooling process (i.e. quenching) leads to higher $\mathrm{Br}^{-} / \mathrm{S}^{2-}$ site-disorder than for samples that were allowed to cool down to room temperature more slowly. The obtained site-disorder for the samples possessing the standard 
cooling procedure are around $22 \%$, compared to site-disorder above $35 \%$ for the quenched materials. The site-disorder obtained by standard cooling is similar to the one usually found for $\mathrm{Li}_{6} \mathrm{PS}_{5} \mathrm{Br},{ }^{19,21}$ which is synthesized via a typical solid-state synthesis route that normally uses 14 days of synthesis time at $823 \mathrm{~K}$. As only the rapid-cooling process leads to higher disorder, these data suggest that rapid cooling kinetically traps a high degree of site-disorder, whereas slower cooling allows for the ordering of $\mathrm{Br}^{-}$and $\mathrm{S}^{2-}$ anions for thermodynamic stability. In order to test if an even slower cooling procedure can further affect the site-disorder, a sample of the ball-milled precursor was treated at $823 \mathrm{~K}$ and allowed to slowly cool for 5 days with a cooling rate of $4 \mathrm{~K} / \mathrm{h}$. Here, a site-disorder of $13 \%$ was observed see Supporting Information for the diffraction pattern (Figure S7), further corroborating that while at elevated temperatures a higher site-disorder seems to be prevalent, a more ordered state is preferred at lower temperatures. These data suggest that rapid cooling kinetically traps higher site-disorder, whereas slow cooling allows for an ordering of the $\mathrm{Br}^{-}$and $\mathrm{S}^{2-}$ anions for thermodynamic stability as the structure relaxes.
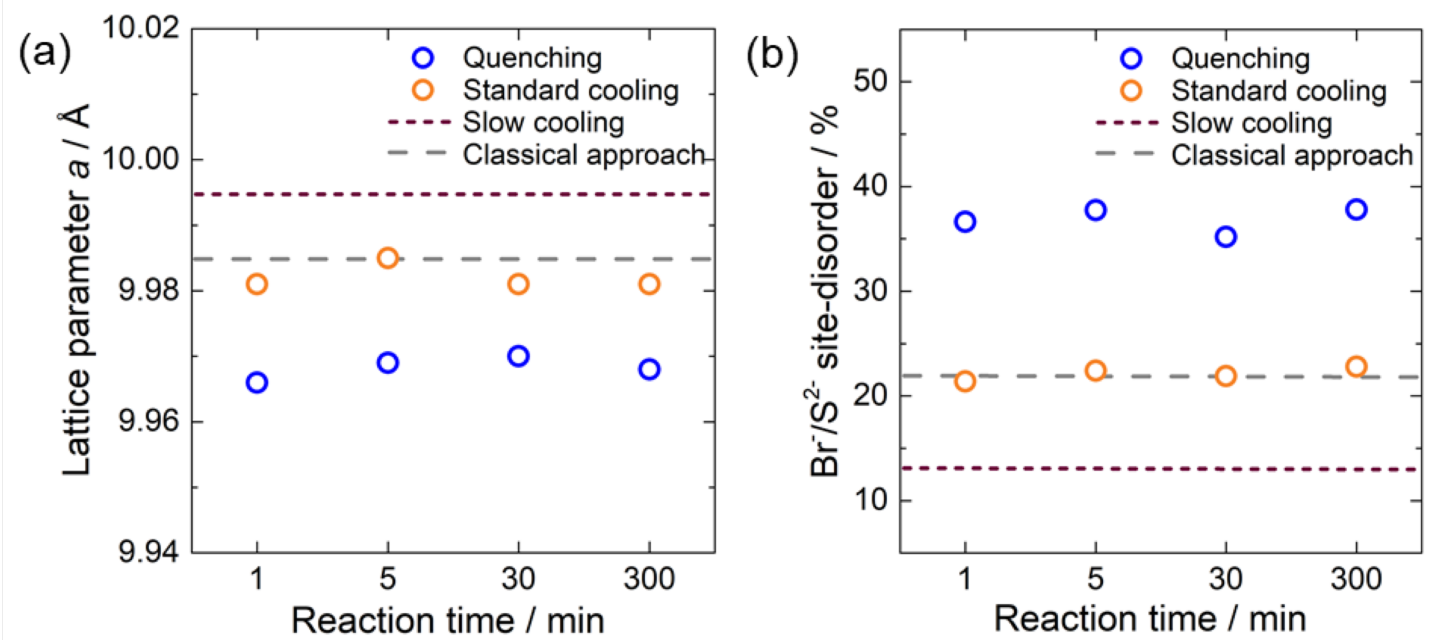

Figure 3: Relevant structural data extracted from the Rietveld refinements. (a) Changes in the lattice parameters between the employed cooling methods. (b) $\mathrm{Br}^{-} / \mathrm{S}^{2-}$ site-disorder in the same samples, where the higher degree of disorder is kinetically trapped by the rapid rate of cooling. Dashed lines indicating the values obtained from the classical approach and the slow cooling procedure for reference. Errors not shown are smaller than the symbol.

Rapid crystallization. Lithium argyrodites are usually synthesized via a solid-state synthesis and a reaction time of 7-14 days to ensure crystallization and full reaction between the precursors, ${ }^{19,21,43}$ or through initial milling of the precursors to ensure better mixing and typical reaction times of a few hours. ${ }^{4,23,44-46}$ The data above show that milling and subsequent annealing without quenching lead to similar results in terms of the site-disorder, suggesting that 
mechanical alloying does not affect the site-disorder directly. More importantly, a rapid crystallization within one minute of reaction time leads to a fully crystalline argyrodite. Figure 4 shows the X-ray diffraction patterns, the Raman spectra after milling (i.e. before crystallization) and after one minute of reaction time and subsequent quenching as well as a pair distribution function of the milled precursors. The diffraction pattern of the milled precursors shows a large amorphous phase suggesting an underlying Li-P-S-X glass phase, however, a fraction of crystalline binary precursors of $\mathrm{LiBr}$ and $\mathrm{Li}_{2} \mathrm{~S}$ are still visible. As recently shown for the lithium thiophosphate glasses, ${ }^{18}$ Raman spectroscopy can be used to assess the local thiophosphate tetrahedra. In both spectra, the ortho-thiophosphate unit $\mathrm{PS}_{4}{ }^{3-}$ is visible at $421 \mathrm{~cm}^{-1}$ as the dominant peak, showing that after milling, the desired thiophosphate units have already been formed (Figure $4 \mathrm{~b}$ ). In addition, some $\mathrm{P}_{2} \mathrm{~S}_{6}{ }^{4-}$ and residual $\mathrm{Li}_{2} \mathrm{~S}$ are found in the Raman spectrum of the milled sample, showing that reaction to form the argyrodite structure is not fully complete. Figure $4 \mathrm{c}$ shows a qualitative analysis of the pair distribution function of the milled precursors compared to a calculated $\mathrm{G}(\mathrm{r})$ of a $\mathrm{Li}_{2} \mathrm{~S} / \mathrm{LiBr} / \mathrm{Li}_{6} \mathrm{PS}{ }_{5} \mathrm{Br}$ mixture and an experimental pair distribution function of $\mathrm{Li}_{6} \mathrm{PS}_{5} \mathrm{Br}$ after classic solid-state synthesis (as taken from Kraft et al. ${ }^{19}$ ). In line with the X-ray diffraction patterns and the Raman spectra, certain bond lengths suggest pre-formed argyrodite to exist together with some unreacted precursor phases.

These data show that mechanical milling not only leads to better mixing of the precursors, but already facilitates reactions of $\mathrm{Li}_{2} \mathrm{~S}$ with $\mathrm{P}_{4} \mathrm{~S}_{10}$ to form ortho-thiophosphate species and possible nucleation clusters of the argyrodite. While a crystalline argyrodite is clearly not yet formed and some unreacted $\mathrm{LiBr}$ and $\mathrm{Li}_{2} \mathrm{~S}$ can still be found, the pre-reaction provides the pathway for the here-observed ultra-fast crystallization and phase formation within one minute of reaction time. Nevertheless, despite a possible formation of argyrodite nucleation clusters, such a fast phase formation and crystallization remains remarkable. 

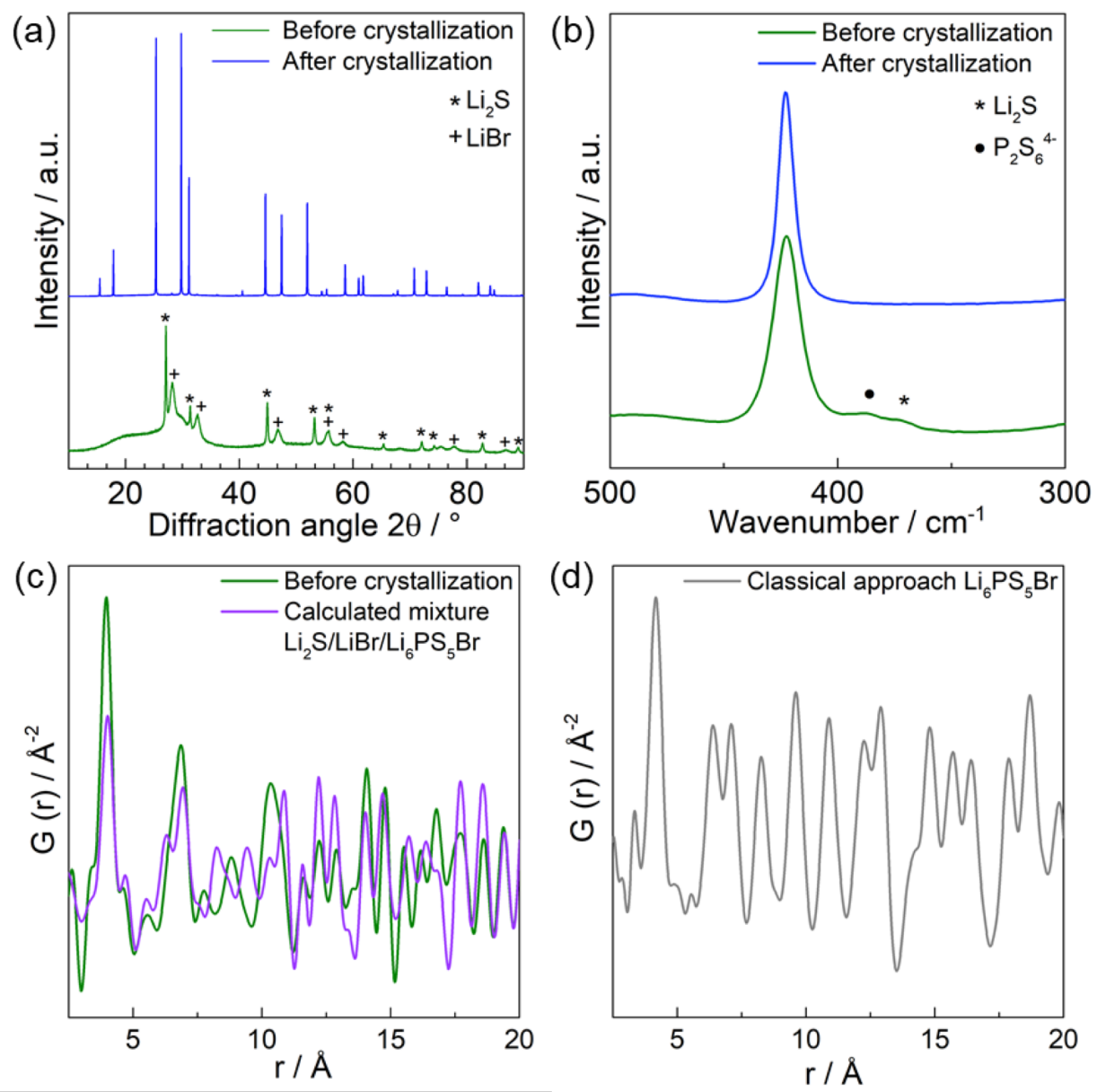

Figure 4: (a) X-ray diffraction patterns of the mechanically milled precursors $\mathrm{Li}_{2} \mathrm{~S}, \mathrm{P}_{4} \mathrm{~S}_{10}$ and $\mathrm{LiBr}$ in comparison to $\mathrm{Li}_{6} \mathrm{PS}_{5} \mathrm{Br}$ after one minute of reaction time and quenching, denoted as before and after crystallization, respectively. (b) Raman spectra before and after crystallization showing that during the milling process, predominantly ortho-thiophosphate units (at $421 \mathrm{~cm}^{-}$ 1) are forming. (c) Pair distribution function $G(r)$ before crystallization in comparison to a calculated mixture of $\mathrm{Li}_{2} \mathrm{~S} / \mathrm{LiBr} / \mathrm{Li}_{6} P \mathrm{~S}_{5} \mathrm{Br}$. d) An experimental $\mathrm{G}(\mathrm{r})$ of a classically synthesized $\mathrm{Li}_{6} \mathrm{PS}_{5} \mathrm{Br}$ taken from Kraft et al. ${ }^{19}$

Influence of reaction procedure on the ionic transport. The site-disorder in the argyrodites has been shown to increase the ionic conductivity by providing additional diffusion pathways. ${ }^{5,25,30}$ In order to assess changes to the ionic conductivity due to the changing crystallization procedure, temperature-dependent impedance spectroscopy measurements were performed. Representative impedance responses for $\mathrm{Li}_{6} \mathrm{PS}_{5} \mathrm{Br}$ at $253 \mathrm{~K}$ after one minute of heat treatment for the standard cooled and quenched samples can be found in Figure 5a, along with their Arrhenius plots (Figure 5b), while all other impedance spectra are shown in the Supporting Information (Figure S8). The impedance data were fit with an equivalent circuit consisting of one parallel constant phase element $(\mathrm{CPE})$ /resistor in series with a CPE, representing the gold 
blocking electrodes. It should be noted that at elevated temperatures, the CPE/resistor has shifted to frequencies that are too high to measure with the impedance analyzer and only the tail of the blocking electrodes was used for the fit. The resolvable impedance spectra exhibit $\alpha$ values of $>0.9$, representing the ideality of the $\mathrm{CPE},{ }^{47}$ and geometric capacitances around 3 to $7 \times 10^{-11} \mathrm{~F} \mathrm{~cm}^{-2}$. Bulk and grain boundary contributions cannot be de-convoluted; however, the obtained ideality of the semicircle and capacitances corresponds well with bulk transport, ${ }^{48}$ as typically observed for these $\mathrm{Li}^{+}$conducting argyrodites. ${ }^{5,19-21}$

The obtained ionic conductivities at room temperature and the activation barriers for the slowlycooled and quenched materials against the different annealing times are shown in Figure $5 \mathrm{c}$ and $\mathrm{d}$, respectively. While no significant influence of the time and synthetic process can be found with respect to the activation barrier, all samples that were subjected to the rapid cooling via quenching exhibit consistently higher ionic conductivities than with a slower cooling rate.
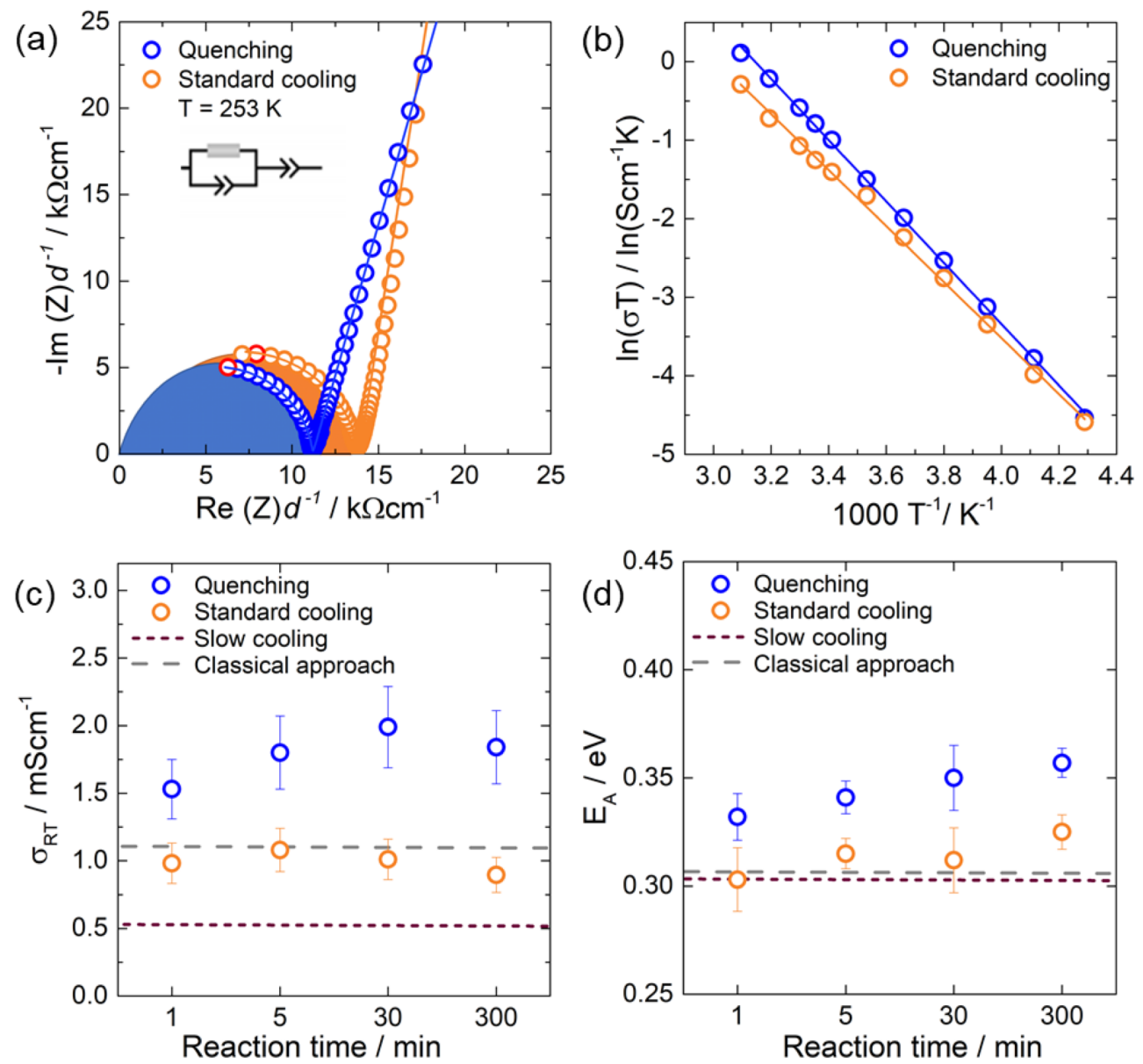

Figure 5: (a) Nyquist plots for the $t=1$ min standard cooled and quenched Li6 $P S_{5} B r$ products, showing the impedance response (open circles) and the fits with the employed equivalent circuit. The apex frequencies of the semicircles are $\sim 0.8 \mathrm{MHz}$ (red circles) and a bulk capacitance of $\sim 3$ to $7 \times 10^{-11} \mathrm{~F} \mathrm{~cm}^{-2}$ is found. (b) Representative Arrhenius plots of the 
conductivity values for the $t=1$ min standard cooled and quenched $L_{6} P S_{5} B r$ products obtained from temperature-dependent impedance spectroscopy. (c) Room-temperature ionic conductivity and (d) activation barrier $E_{A}$ as a function of reaction time. Dashed lines indicating the values obtained from the classical approach and the slow cooling procedure have been added for reference.

Observations from ab-initio molecular dynamics. In order to assess the influence of the disorder on the ionic transport as seen in the experimental data shown above for $\mathrm{Li}_{6} \mathrm{PS}_{5} \mathrm{Br}$, ab-initio molecular dynamics simulations were performed on a fully ordered structure and two structure sets with $25 \%$ and $50 \% \mathrm{Br}^{-} / \mathrm{S}^{2-}$ site-disorder. While these anion arrangements do not exactly represent the observed site-disorder, the structures with $25 \%$ site-disorder can be viewed as representatives for the standard cooling approach and structures with $50 \%$ site-disorder represent the quenching approach. The ordered structure serves as reference system for comparison.
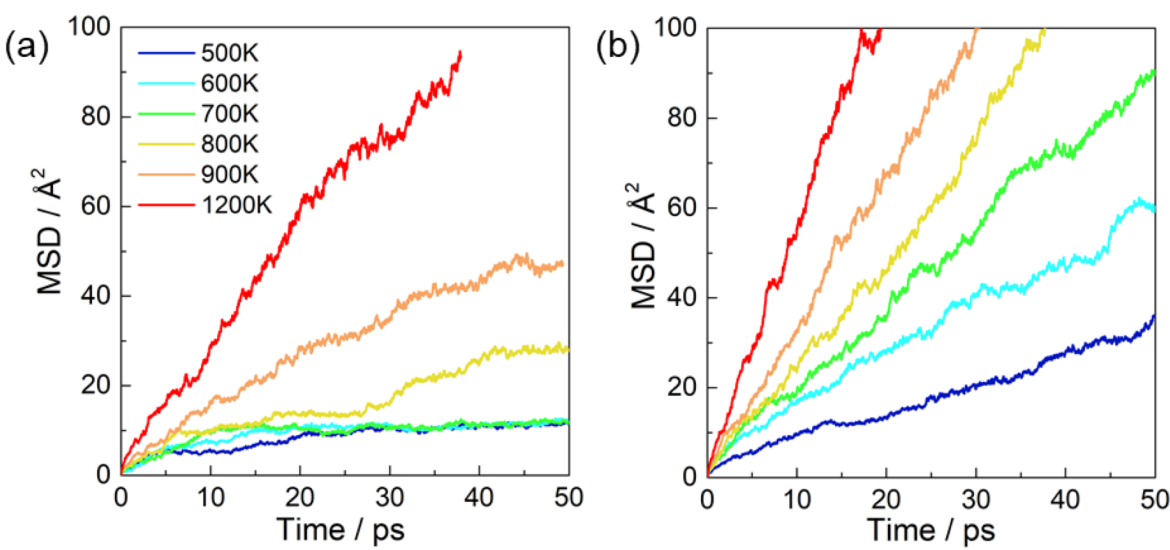

(c)

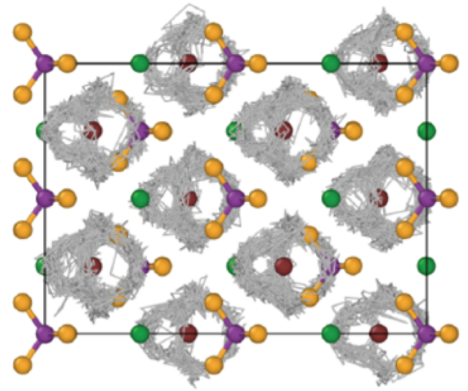

(d)

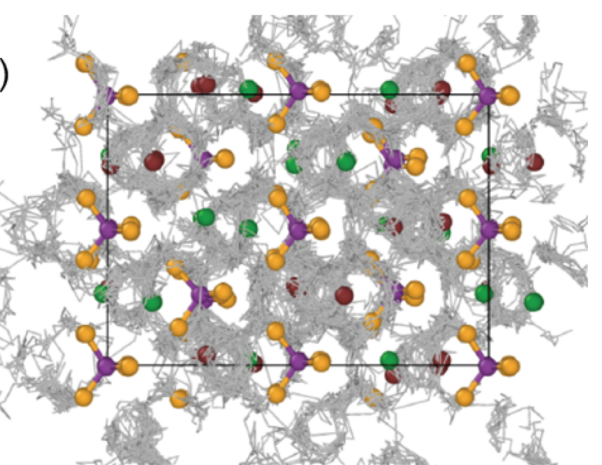

Figure 6: Mean-square displacement (MSD) $\mathrm{Li}^{+}$in a $\mathrm{Li}_{6} \mathrm{PS} \mathrm{S}_{5} \mathrm{Br}$ structure without $\mathrm{Br}^{-} / \mathrm{S}^{2-}$ disorder (a) and with $50 \% \mathrm{Br}^{-} / \mathrm{S}^{2-}$ site-disorder (b). Representative $\mathrm{Li}^{+}$trajectories at $700 \mathrm{~K}$ for 35 ps are shown for the fully ordered (c) and disordered (d) structure. The disorder leads to larger mean square displacements of the cations and successful jumps can be found between the $\mathrm{Li}^{+}$cages only if disorder is present. 
The temporal evolution of the $\mathrm{Li}^{+}$mean-square displacements (MSD) of the ordered and a representative structure with $50 \%$ site-disorder are shown in Figure 6. For temperatures of 500 $\mathrm{K}, 600 \mathrm{~K}$, and $700 \mathrm{~K}$ the mean-square displacements of the ordered structure saturate at approximately $10 \AA^{2}$ after several picoseconds' simulation time, whereas the MSD of the disordered structures steadily increases. Only at temperatures of $700 \mathrm{~K}$ and above do the MSD of the ordered structure increase with increasing simulation time, similar to the disordered structure. These differences in the MSD can be explained by the intra-cage and inter-cage jumps in $\mathrm{Li}_{6} \mathrm{PS}_{5} \mathrm{Br}$ by visualizing the $\mathrm{Li}^{+}$trajectories for an exemplary temperature of $700 \mathrm{~K}$ (see Figure $6 \mathrm{c}$ and $\mathrm{d}$ ). The $\mathrm{Li}^{+}$trajectories for the remaining temperatures of all assessed sitedisorders can be found in the Supporting Information Figure $\mathrm{S} 10$. $\mathrm{The}^{+} \mathrm{i}^{+}$trajectories suggest that doublet and intra-cage jumps dominate at lower temperatures for the ordered phase. The distance from one side of a cage to the opposite side is roughly $4.5 \AA$. If all $\mathrm{Li}^{+}$would move to the opposite side of their cage at the same time a MSD of $(4.5 \AA)^{2} \approx 20 \AA^{2}$ could be expected. This scenario is rather improbable and most frequently only a part of the $\mathrm{Li}^{+}$ions will have traveled to the opposite side, while the rest may still be located on their initial positions leading to a reduced $\mathrm{MSD}<20 \AA^{2}$. The $\mathrm{Br}^{-} / \mathrm{S}^{2-}$ site-disorder dissolves the strictly separated cage structure of $\mathrm{Li}_{6} \mathrm{PS}_{5} \mathrm{Br}$ and enables more low-energy diffusion pathways throughout the material that are active already at lower temperatures. ${ }^{22}$ In other words, at lower temperatures within the ordered structure, only jumps within the $\mathrm{Li}^{+}$cages can be found, whereas the disordering allows for jumps between the cages that ultimately correspond to long-range transport.

The $\mathrm{Li}^{+}$tracer diffusion coefficient $\mathrm{D}_{\text {tr }}$ has been extracted from a linear fit of the MSD evolution over time ${ }^{49}$ after 5 ps of equilibration time. As there is no long-range transport at $500 \mathrm{~K}, 600 \mathrm{~K}$ and $700 \mathrm{~K}$ in the ordered phase during the simulation this approach fails for these temperatures. However, it is applicable for higher temperatures in the ordered and all temperatures in the disordered structures that are also considered here. In Figure 7, the obtained $D_{\text {tr }}$ of the ordered structure are shown together with the $\mathrm{D}_{\text {tr }}$ averaged over all the structures with $25 \%$ and $50 \%$ site-disorder. Certain trends are clearly visible: (1) the introduction of $\mathrm{Br}^{-} / \mathrm{S}^{2-}$ site-disorder leads to increased $\mathrm{D}_{\text {tr }}$ compared to the ordered phase. For instance, at $800 \mathrm{~K}$ the smallest observed $\mathrm{D}_{\text {tr }}$ of a $50 \%$ disordered phase was found to be still a factor of three times larger compared to the ordered phase. With further increasing temperatures, the difference between $D_{\text {tr }}$ of the ordered and the disordered phases decreases as more and more thermal energy is provided to overcome the slightly higher activation barriers. Here, the missing disorder clearly has a much higher energy barrier, as was recently shown for $\mathrm{Li}_{6+{ }_{x}} \mathrm{P}_{1-x} \mathrm{M}_{x} \mathrm{~S}_{5} \mathrm{I}$ (with $\mathrm{M}=\mathrm{Si}, \mathrm{Ge}$ ). ${ }^{5,30}$ (2) 
Structures with $50 \%$ site-disorder show enhanced diffusivity compared to structures with $25 \%$ site-disorder due to an increasing Arrhenius pre-factor, explaining the experimentally observed increase of the ionic conductivity. However, while an increase of the activation barriers is observed experimentally (see Figure 5), likely due to the compensation rule (see Supporting Information Figure S11), ${ }^{50,51}$ the simulations do not capture this behavior possibly due to the typical underestimation of migration barriers..$^{52}$

Overall, these calculations are in line with the literature ${ }^{22}$ and our experimental results. The calculations suggest that in disordered phases, the tracer diffusion coefficient of $\mathrm{Li}^{+}$is higher than in the ordered phase and that a higher degree of $\mathrm{Br}^{-} / \mathrm{S}^{2-}$ site-disorder leads to enhanced transport properties.

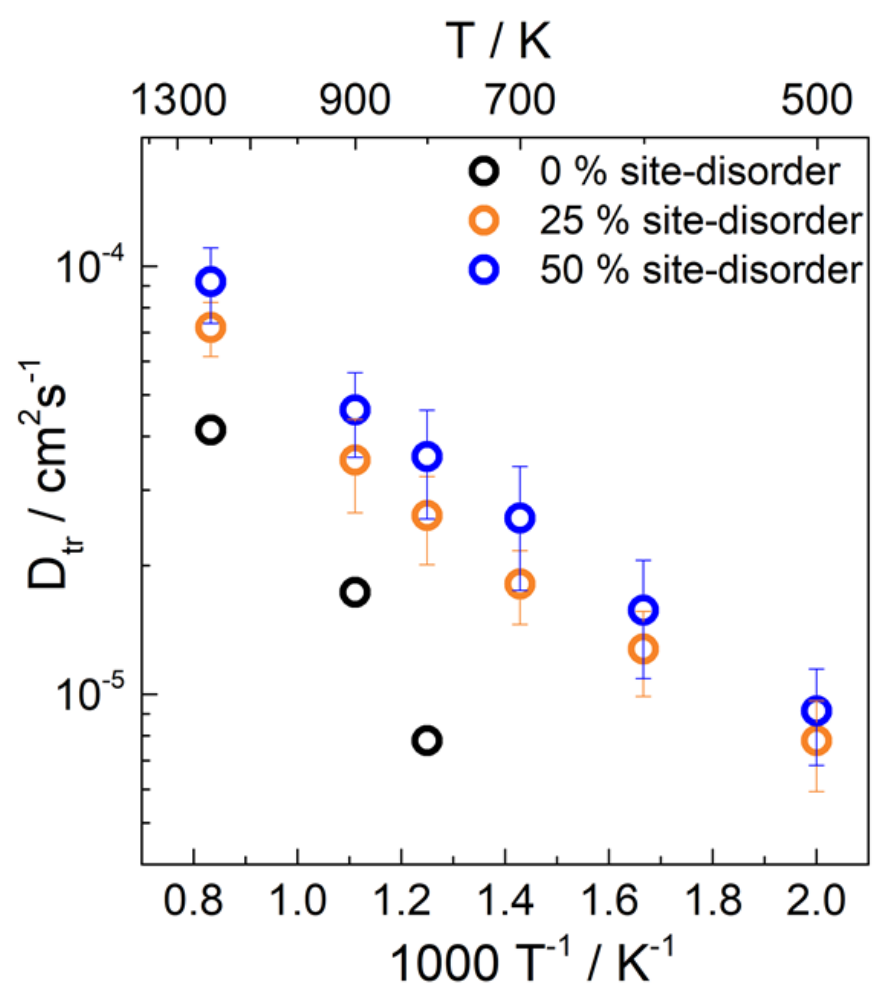

Figure 7: Arrhenius plot of the average $\mathrm{Li}^{+}$tracer diffusion coefficients $D_{\text {tr }}$ for the ordered phase and the disordered structures with an overall $25 \%$ and $50 \% \mathrm{Br}^{-} / \mathrm{S}^{2-}$ site-disorder. While long-range diffusion and jumps between the $\mathrm{Li}^{+}$cages can be only at elevated temperatures above $700 \mathrm{~K}$ for the ordered phase, all disordered structures show an increased diffusion coefficient at all temperatures.

Influence of site-disorder on the ionic transport. Figure 8 shows the experimentally obtained conductivities versus the refined site-disorder for the classically synthesized $\mathrm{Li}_{6} \mathrm{PS}_{5} \mathrm{X}(\mathrm{X}=\mathrm{Cl}$, $\mathrm{Br}$, I) from Kraft et al., ${ }^{19}$ along with the quenched, standard cooling, and slow cooling $\mathrm{Li}_{6} \mathrm{PS}_{5} \mathrm{Br}$ from this work. With increasing site-disorder, the conductivity increases, likely due to more 
conducting channels, i.e. more percolation pathways and with it higher Arrhenius pre-factors, as recently demonstrated for $\mathrm{Li}_{6+x} \mathrm{P}_{1-x} \mathrm{M}_{x} \mathrm{~S} \mathrm{~S}_{5} \mathrm{I}$ (with $\mathrm{M}=\mathrm{Si}, \mathrm{Ge}$ ). ${ }^{5,30}$ While the $\mathrm{Li}_{6} \mathrm{PS}_{5} \mathrm{Br}$ cooled at the standard rate shows disorder and conductivities of the classically-prepared argyrodites, the slow cooling over 5 days, and with it lower disorder, leads to even lower conductivities. In contrast, the kinetic trapping of the site-disorder by quenching leads to more conducting channels and higher ionic conductivities, whereas the activation barrier remains unchanged as site-disorder already exists in all samples. ${ }^{5}$ This work provides further evidence that the sitedisorder in the lithium argyrodites is decisive for the ionic transport and that it can be modulated by tuning the rate of cooling during the crystallization process. Moreover, this work highlights the rapid crystallization rates that are accessible using mechanical alloying approaches, given that a crystalline $\mathrm{Li}_{6} \mathrm{PS}_{5} \mathrm{Br}$ argyrodite can be obtained after only one minute of crystallization time.

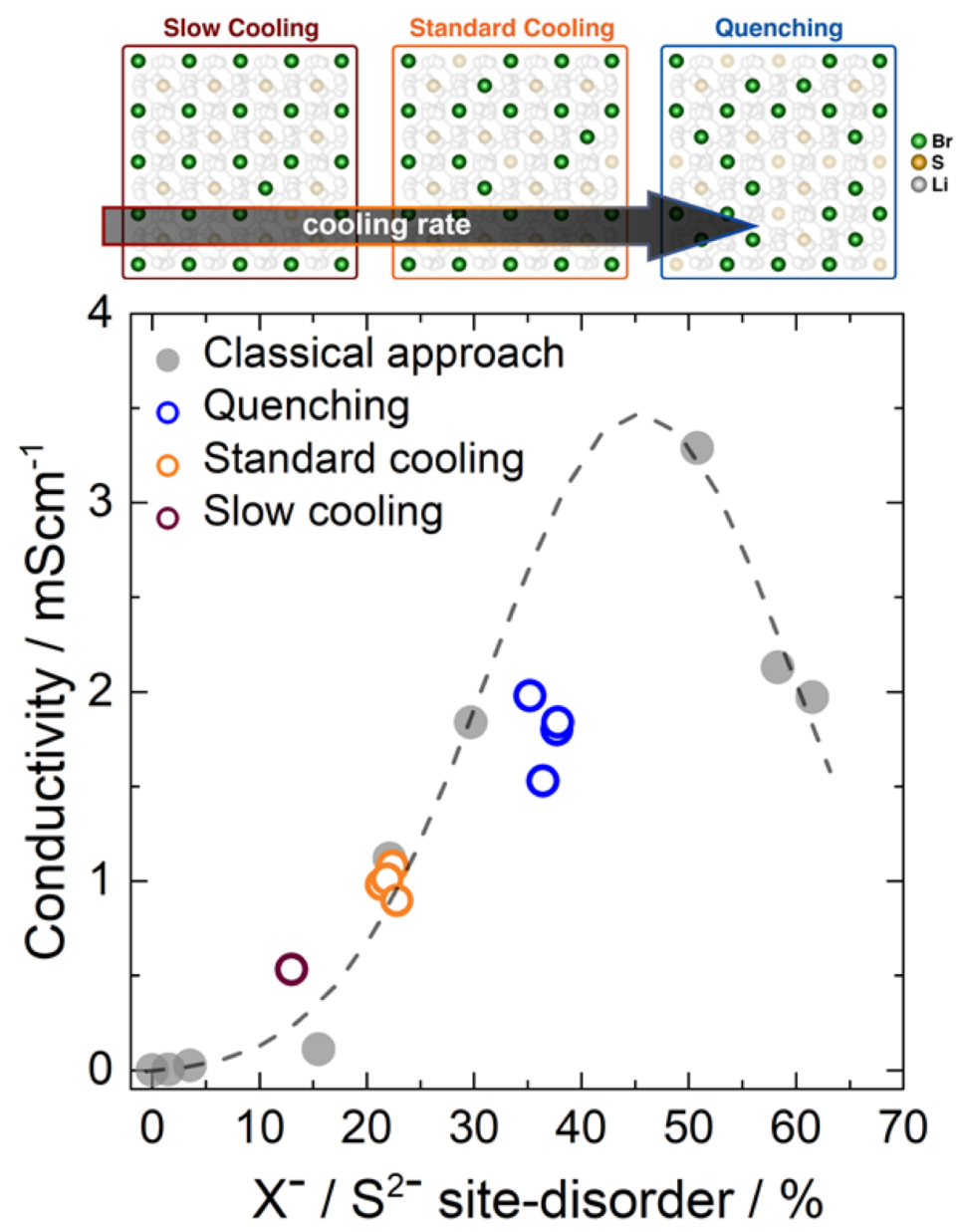

Figure 8: Comparison of conductivities vs. $\mathrm{Br}^{-} / \mathrm{S}^{2-}$ site-disorder of classically synthesized $\mathrm{Li}_{6} \mathrm{PS}_{5} \mathrm{X}\left(\mathrm{X}=\mathrm{Cl}, \mathrm{Br}, \mathrm{I}\right.$; data taken from Kraft et al. $\left.{ }^{19}\right)$ with the standard cooled and quenched $\mathrm{Li}_{6} \mathrm{PS} \mathrm{S}_{5} \mathrm{Br}$ as well as the $\mathrm{Li}_{6} \mathrm{PS} \mathrm{S}_{5} \mathrm{Br}$ that has been cooled down over a period of 5 days (this work). A guide to the eye shows the influence of site-disorder on the ionic conductivity. The schematic 
shows that with increasing site-disorder, low-energy percolation pathways open up that lead to an increase in the ionic conductivity.

\section{Conclusion}

In this work, we demonstrated that crystalline argyrodites can be obtained even after just one minute of heat treatment after mechanical alloying of the precursors. This ultra-fast crystallization shows that mechanical alloying already acts as a primary synthetic step and that the typically long reaction times are not needed for the synthesis of lithium argyrodites. In addition, the correlation between the site-disorder and the conductivity observed here provides further evidence that disorder in superionic materials such as the argyrodites is beneficial for ionic transport and that it can be controlled synthetically. It shows that rapid cooling of argyrodites can kinetically freeze local site-disorder and hence provides a novel optimization technique in the field of superionic conductors.

\section{Supporting Information}

All structural data as obtained from Rietveld refinements, comparison of impedance spectra between different quenching routines, Williamson-Hall analysis, $\mathrm{Li}^{+}$trajectories at different temperatures from the computational studies as well as a Meyer-Neldel plot of the Arrheniusprefactors and activation barriers.

\section{AUTHOR INFORMATION}

\section{Corresponding Authors}

*wolfgang.g.zeier@pc.jlug.de;

\section{Notes}

The authors declare no competing financial interests.

\section{Acknowledgements}

The research was supported by the Federal Ministry of Education and Research (BMBF) within the project FESTBATT under grant number 03XP0177A and 03XP0174A. S.C. gratefully 
acknowledges the Alexander von Humboldt Foundation for financial support through a Postdoctoral Fellowship. N.P. and M.Z. thank the Deutsche Forschungsgemeinschaft DFG within the priority program SPP 2080, grant number ZO 369/2-1 and the Bavarian Polymer Institute (BPI) for funding. Calculations for this research were conducted on the Lichtenberg high performance computer of the TU Darmstadt.

\section{References}

(1) Janek, J.; Zeier, W. G. A Solid Future for Battery Development. Nat. Energy 2016, 1, 16141.

(2) Culver, S. P.; Krauskopf, T.; Koerver, R.; Zeier, W. G. Designing Ionic Conductors: The Interplay between Structural Phenomena and Interfaces in Thiophosphatebased SolidState Batteries. Chem. Mater. 2018, 30, 4179-4192.

(3) Kato, Y.; Hori, S.; Saito, T.; Suzuki, K.; Hirayama, M.; Mitsui, A.; Yonemura, M.; Iba, H.; Kanno, R. High-Power All-Solid-State Batteries Using Sulfide Superionic Conductors. Nat. Energy 2016, 1, 16030.

(4) Wang, H.; Yu, C.; Ganapathy, S.; van Eck, E. R. H.; van Eijck, L.; Wagemaker, M. A Lithium Argyrodite $\mathrm{Li}_{6} \mathrm{PS}_{5} \mathrm{Cl}_{0.5} \mathrm{Br}_{0.5}$ Electrolyte with Improved Bulk and Interfacial Conductivity. J. Power Sources 2019, 412, 29-36.

(5) Kraft, M. A.; Ohno, S.; Zinkevich, T.; Koerver, R.; Culver, S. P.; Senyshyn, A.; Indris, S.; Morgan, B. J.; Zeier, W. G. Inducing High Ionic Conductivity in the Lithium Superionic Argyrodites $\mathrm{Li}_{6+x} \mathrm{P}_{1-x} \mathrm{Ge}_{x} \mathrm{~S}_{5} \mathrm{I}$ for All-Solid-State Batteries. J. Am. Chem. Soc. 2018, 140, 16330-16339.

(6) Koerver, R.; Zhang, W.; de Biasi, L.; Schweidler, S.; Kondrakov, A. O.; Kolling, S.; Brezesinski, T.; Hartmann, P.; Zeier, W. G.; Janek, J. Chemo-Mechanical Expansion of Lithium Electrode Materials - on the Route to Mechanically Optimized All-Solid-State Batteries. Energy Environ. Sci. 2018, 11, 2142-2158.

(7) Koerver, R.; Aygün, I.; Leichtweiß, T.; Dietrich, C.; Zhang, W.; Binder, J. O.; Hartmann, P.; Zeier, W. G.; Janek, J. Capacity Fade in Solid-State Batteries: Interphase Formation and Chemomechanical Processes in Nickel-Rich Layered Oxide Cathodes and Lithium Thiophosphate Solid Electrolytes. Chem. Mater. 2017, 29, 5574-5582.

(8) Auvergniot, J.; Cassel, A.; Ledeuil, J. B.; Viallet, V.; Seznec, V.; Dedryvère, R. Interface Stability of Argyrodite $\mathrm{Li}_{6} \mathrm{PS}_{5} \mathrm{Cl}$ toward $\mathrm{LiCoO}_{2}, \mathrm{LiNi}_{1 / 3} \mathrm{Co}_{1 / 3} \mathrm{Mn}_{1 / 3} \mathrm{O}_{2}$, and $\mathrm{LiMn}_{2} \mathrm{O}_{4}$ in Bulk All-Solid-State Batteries. Chem. Mater. 2017, 29, 3883-3890. 
(9) Yu, C.; Ganapathy, S.; van Eck, E. R. H.; van Eijck, L.; de Klerk, N.; Kelder, E. M.; Wagemaker, M. Investigation of Li-Ion Transport in $\mathrm{Li}_{7} \mathrm{P}_{3} \mathrm{~S}_{11}$ and Solid-State Lithium Batteries. J. Energy Chem. 2019, 38, 1-7.

(10) Kamaya, N.; Homma, K.; Yamakawa, Y.; Hirayama, M.; Kanno, R.; Yonemura, M.; Kamiyama, T.; Kato, Y.; Hama, S.; Kawamoto, K.; et al. A Lithium Superionic Conductor. Nat. Mater. 2011, 10, 682-686.

(11) Krauskopf, T.; Culver, S. P.; Zeier, W. G. The Bottleneck of Diffusion and Inductive Effects in $\mathrm{Li}_{10} \mathrm{Ge}_{1-x} \mathrm{Sn}_{x} \mathrm{P}_{2} \mathrm{~S}_{12}$. Chem. Mater. 2018, 30, 1791-1798.

(12) Weber, D. A.; Senyshyn, A.; Weldert, K. S.; Wenzel, S.; Zhang, W.; Kaiser, R.; Berendts, S.; Janek, J.; Zeier, W. G. Structural Insights and 3D Diffusion Pathways within the Lithium Superionic Conductor $\mathrm{Li}_{10} \mathrm{GeP}_{2} \mathrm{~S}_{12}$. Chem. Mater. 2016, 28, 59055915.

(13) Kuhn, A.; Gerbig, O.; Zhu, C.; Falkenberg, F.; Maier, J.; Lotsch, B. V. A New Ultrafast Superionic Li-Conductor: Ion Dynamics in $\mathrm{Li}_{11} \mathrm{Si}_{2} \mathrm{PS}_{12}$ and Comparison with Other Tetragonal LGPS-Type Electrolytes. Phys. Chem. Chem. Phys. 2014, 16, 14669-14674.

(14) Kuhn, A.; Duppel, V.; Lotsch, B. V. Tetragonal $\mathrm{Li}_{10} \mathrm{GeP}_{2} \mathrm{~S}_{12}$ and $\mathrm{Li}_{7} \mathrm{GePS}_{8}-$ Exploring the Li Ion Dynamics in LGPS Li Electrolytes. Energy Environ. Sci. 2013, 6, 3548-3552.

(15) Zhang, Z.; Shao, Y.; Lotsch, B.; Hu, Y. S.; Li, H.; Janek, J.; Nazar, L. F.; Nan, C. W.; Maier, J.; Armand, M.; et al. New Horizons for Inorganic Solid State Ion Conductors. Energy Environ. Sci. 2018, 11, 1945-1976.

(16) Seino, Y.; Nakagawa, M.; Senga, M.; Higuchi, H.; Takada, K.; Sasaki, T. Analysis of the Structure and Degree of Crystallisation of $70 \mathrm{Li}_{2} \mathrm{~S}-30 \mathrm{P}_{2} \mathrm{~S}_{5}$ Glass Ceramic. J. Mater. Chem. A 2015, 3, 2756-2761.

(17) Seino, Y.; Ota, T.; Takada, K.; Hayashi, A.; Tatsumisago, M. A Sulphide Lithium Super Ion Conductor Is Superior to Liquid Ion Conductors for Use in Rechargeable Batteries. Energy Environ. Sci. 2014, 7, 627-631.

(18) Dietrich, C.; Weber, D.; Sedlmaier, S. J.; Indris, S.; Culver, S.; Walter, D.; Janek, J.; Zeier, W. Lithium Ion Conductivity in $\mathrm{Li}_{2} \mathrm{~S}-\mathrm{P}_{2} \mathrm{~S}_{5}$ Glasses - Building Units and Local Structure Evolution during the Crystallization of the Superionic Conductors $\mathrm{Li}_{3} \mathrm{PS}_{4}$, $\mathrm{Li}_{7} \mathrm{P}_{3} \mathrm{~S}_{11}$ and $\mathrm{Li}_{4} \mathrm{P}_{2} \mathrm{~S}_{7}$. J. Mater. Chem. A 2017, 5, 18111-18119.

(19) Kraft, M. A.; Culver, S. P.; Calderon, M.; Böcher, F.; Krauskopf, T.; Senyshyn, A.; Dietrich, C.; Zevalkink, A.; Janek, J.; Zeier, W. G. Influence of Lattice Polarizability on the Ionic Conductivity in the Lithium Superionic Argyrodites $\mathrm{Li}_{6} \mathrm{PS}_{5} \mathrm{X}(\mathrm{X}=\mathrm{Cl}, \mathrm{Br}, \mathrm{I}) . J$. Am. Chem. Soc. 2017, 139, 10909-10918. 
(20) Bernges, T.; Culver, S. P.; Minafra, N.; Koerver, R.; Zeier, W. G. Competing Structural Influences in the Li Superionic Conducting Argyrodites $\mathrm{Li}_{6} \mathrm{PS}_{5-x} \mathrm{Se} e_{x} \mathrm{Br}(0 \leq \mathrm{x} \leq 1)$ upon Se Substitution. Inorg. Chem. 2018, 57, 13920-13928.

(21) Minafra, N.; Culver, S. P.; Krauskopf, T.; Senyshyn, A.; Zeier, W. G. Effect of Si Substitution on the Structural and Transport Properties of Superionic Li-Argyrodites. $J$. Mater. Chem. A 2018, 6, 645-651.

(22) de Klerk, N. J. J.; Rosłoń, I.; Wagemaker, M. Diffusion Mechanism of Li Argyrodite Solid Electrolytes for Li-Ion Batteries and Prediction of Optimized Halogen Doping: The Effect of Li Vacancies, Halogens, and Halogen Disorder. Chem. Mater. 2016, 28, 79557963.

(23) Yu, C.; Ganapathy, S.; de Klerk, N. J. J.; Roslon, I.; van Eck, E. R. H.; Kentgens, A. P. M.; Wagemaker, M. Unravelling Li-Ion Transport from Picoseconds to Seconds: Bulk versus Interfaces in an Argyrodite $\mathrm{Li}_{6} \mathrm{PS}_{5} \mathrm{Cl}-\mathrm{Li}_{2} \mathrm{~S}$ All-Solid-State Li-Ion Battery. J. Am. Chem. Soc. 2016, 138, 1192-11201.

(24) Zhou, L.; Park, K.-H.; Sun, X.; Lalere, F.; Adermann, T.; Hartmann, P.; Nazar, L. F. Solvent-Engineered Design of Argyrodite $\mathrm{Li}_{6} \mathrm{PS}_{5} \mathrm{X}(\mathrm{X}=\mathrm{Cl}, \mathrm{Br}$, I) Solid Electrolytes with High Ionic Conductivity. ACS Energy Lett. 2019, 4, 265-270.

(25) Adeli, P.; Bazak, J. D.; Park, K. H.; Kochetkov, I.; Huq, A.; Goward, G. R.; Nazar, L. F. Boosting Solid - State Diffusivity and Conductivity in Lithium Superionic Argyrodites by Halide Substitution. Angew. Chemie 2019, 58, 8681-8686.

(26) Adelstein, N.; Wood, B. C. Role of Dynamically Frustrated Bond Disorder in a Li+ Superionic Solid Electrolyte. Chem. Mater. 2016, 28, 7218-7231.

(27) Krauskopf, T.; Culver, S. P.; Zeier, W. G. On the Local Tetragonal Structure of the Cubic Superionic Conductor $\mathrm{Na}_{3} \mathrm{PS}_{4}$. Inorg. Chem. 2018, 57, 4739-4744.

(28) Hanghofer, I.; Brinek, M.; Eisbacher, S. L.; Bitschnau, B.; Volck, M.; Hennige, V.; Hanzu, I.; Rettenwander, D.; Wilkening, H. M. R. Substitutional Disorder: Structure and Ion Dynamics of the Argyrodites $\mathrm{Li}_{6} \mathrm{PS}_{5} \mathrm{Cl}, \mathrm{Li}_{6} \mathrm{PS}{ }_{5} \mathrm{Br}$ and $\mathrm{Li}_{6} \mathrm{PS}_{5} \mathrm{I}$. Phys. Chem. Chem. Phys. 2019, 21, 8489-8507.

(29) Hanghofer, I.; Gadermaier, B.; Wilkening, H. M. R. Fast Rotational Dynamics in Argyrodite-Type $\mathrm{Li}_{6} \mathrm{PS}_{5} \mathrm{X}(\mathrm{X}: \mathrm{Cl}, \mathrm{Br}, \mathrm{I})$ as Seen by ${ }^{31} \mathrm{P}$ Nuclear Magnetic Relaxation On Cation-Anion Coupled Transport in Thiophosphates. Chem. Mater. 2019, 31, 45914597.

(30) Ohno, S.; Helm, B.; Fuchs, T.; Dewald, G.; Kraft, M.; Culver, S.; Senyshyn, A.; Zeier, W. Further Evidence for Energy Landscape Flattening in the Superionic Argyrodites 
$\mathrm{Li}_{6+} \mathrm{P}_{1-x} \mathrm{M}_{x} \mathrm{~S} 5 \mathrm{I}(\mathrm{M}=\mathrm{Si}, \mathrm{Ge}, \mathrm{Sn})$. Chem. Mater. 2019, 31, 4936-4944.

(31) STOE \& Cie GmbH. WinXPOW. Darmstadt, Germany 2011.

(32) A. A. Coelho. TOPAS-Academic. Brisbane, Australia 2007.

(33) Kresse, G.; J. Hafner. Liquid-Metal - Amorphous-Semiconductor. Phys. Rev. B 1994, 49,14251 .

(34) Kresse, G.; Furthmiiller, J. Water News Roundup. J. / Am. Water Work. Assoc. 2004, 6, $15-50$.

(35) Ab Initio Hellmann-Feynman Molecular Dynamics for Liquid Metals. J. Non. Cryst. Solids 1993, 156-158, 956-960.

(36) Kresse, G.; Furthmüller, J.; Li, Y. J.; Chen, Y. J.; Walmsley, J. C.; Mathinsen, R. H.; Dumoulin, S.; Roven, H. J.; Yip, S.; Supervisor, T.; et al. Modeling Microstructural E Ff Ects on Deformation Resistance and Thermal Conductivity. Phys. Rev. B 2000, 62, 11169-11186.

(37) Perdew, J. P.; Burke, K.; Ernzerhof, M. Generalized Gradient Approximation Made Simple - The PBE Functional. Phys. Rev. Lett. 1996, 77, 3865-3868.

(38) Perdew, J. P.; Ernzerhof, M.; Burke, K. [ERRATA] Generalized Gradient Approximation Made Simple. Phys. Rev. Lett. 1997, 78, 3865-3868.

(39) Kresse, G.; Joubert, D. Kresse, Joubert - Unknown - From Ultrasoft Pseudopotentials to the Projector Augmented-Wave Method. 1999, 59, 11-19.

(40) Han, F. Projector Augmented-Wave Method. Phys. Rev. B 1994, 50, 17953-17979.

(41) Okhotnikov, K.; Charpentier, T.; Cadars, S. Supercell Program: A Combinatorial Structure-Generation Approach for the Local-Level Modeling of Atomic Substitutions and Partial Occupancies in Crystals. J. Cheminform. 2016, 8, 1-15.

(42) Stukowski, A. Visualization and Analysis of Atomistic Simulation Data with OVITOthe Open Visualization Tool. Model. Simul. Mater. Sci. Eng. 2010, 18, 015012.

(43) Deiseroth, H. J.; Kong, S. T.; Eckert, H.; Vannahme, J.; Reiner, C.; Zaiß, T.; Schlosser, M. $\mathrm{Li}_{6} \mathrm{PS}_{5} \mathrm{X}$ : A Class of Crystalline Li-Rich Solids with an Unusually High Li+ Mobility. Angew. Chemie - Int. Ed. 2008, 47, 755-758.

(44) Rayavarapu, P. R.; Sharma, N.; Peterson, V. K.; Adams, S. Variation in Structure and Li +-Ion Migration in Argyrodite-Type $\mathrm{Li}_{6} \mathrm{PS}_{5} \mathrm{X}(\mathrm{X}=\mathrm{Cl}, \mathrm{Br}, \mathrm{I})$ Solid Electrolytes. J. Solid State Electrochem. 2012, 16, 1807-1813.

(45) Yu, C.; Ganapathy, S.; Van Eck, E. R. H.; Van Eijck, L.; Basak, S.; Liu, Y.; Zhang, L.; Zandbergen, H. W.; Wagemaker, M. Revealing the Relation between the Structure, LiIon Conductivity and Solid-State Battery Performance of the Argyrodite $\mathrm{Li}_{6} \mathrm{PS}_{5} \mathrm{Br}$ Solid 
Electrolyte. J. Mater. Chem. A 2017, 5, 21178-21188.

(46) Boulineau, S.; Courty, M.; Tarascon, J. M.; Viallet, V. Mechanochemical Synthesis of Li-Argyrodite $\mathrm{Li}_{6} \mathrm{PS}_{5} \mathrm{X}(\mathrm{X}=\mathrm{Cl}, \mathrm{Br}, \mathrm{I})$ as Sulfur-Based Solid Electrolytes for All Solid State Batteries Application. Solid State Ionics 2012, 221, 1-5.

(47) Brug, G. J.; van den Eeden, A. L. G.; Sluyters-Rehbach, M.; Sluyters, J. H. The Analysis of Electrode Impedances Complicated by the Presence of a Constant Phase Element. $J$. Electroanal. Chem. 1984, 176, 275-295.

(48) Irvine, J. T. S.; Sinclair, D. C.; West, A. R. Electroceramics: Characterization by Impedance Spectroscopy. Adv. Mater. 1990, 2, 132-138.

(49) Urban, A.; Seo, D. H.; Ceder, G. Computational Understanding of Li-Ion Batteries. npj Comput. Mater. 2016, 2, 16002.

(50) Krauskopf, T.; Muy, S.; Culver, S. P.; Ohno, S.; Delaire, O.; Shao-Horn, Y.; Zeier, W. G. Comparing the Descriptors for Investigating the Influence of Lattice Dynamics on Ionic Transport Using the Superionic Conductor $\mathrm{Na}_{3} \mathrm{PS}_{4-\mathrm{x}} \mathrm{Se}_{\mathrm{x}} . J$. Am. Chem. Soc. 2018, $140,14464-14473$.

(51) Muy, S.; Bachman, J. C.; Chang, H. H.; Giordano, L.; Maglia, F.; Lupart, S.; Lamp, P.; Zeier, W. G.; Shao-Horn, Y. Lithium Conductivity and Meyer-Neldel Rule in $\mathrm{Li}_{3} \mathrm{PO}_{4}-$ $\mathrm{Li}_{3} \mathrm{VO}_{4}-\mathrm{Li}_{4} \mathrm{GeO}_{4}$ Lithium Superionic Conductors. Chem. Mater. 2018, 30, 5573-5582.

(52) Sicolo, S.; Kalcher, C.; Sedlmaier, S. J.; Janek, J.; Albe, K. Diffusion Mechanism in the Superionic Conductor $\mathrm{Li}_{4} \mathrm{PS}_{4} \mathrm{I}$ Studied by First-Principles Calculations. Solid State Ionics 2018, 319, 83-91. 
For table of contents only

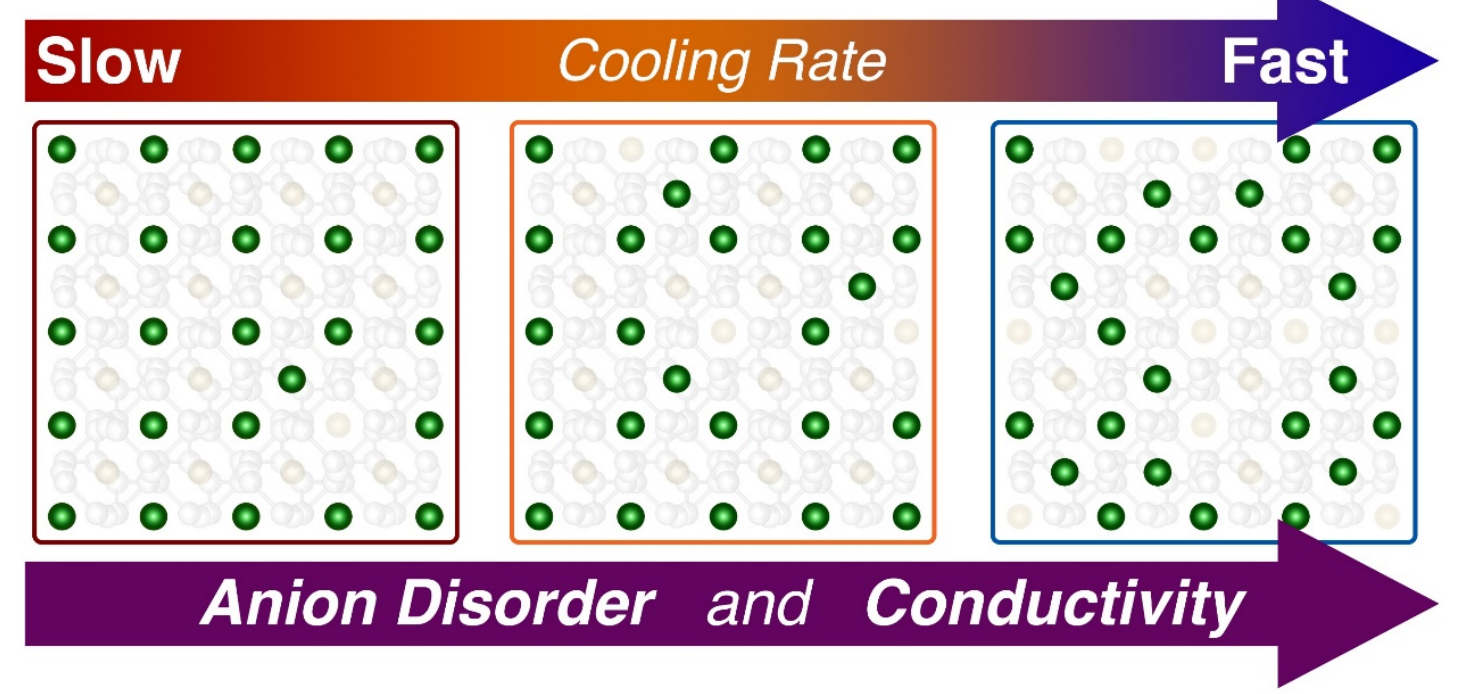




\section{Supporting Information -}

\section{Rapid crystallization and kinetic freezing of high site- disorder in the lithium superionic argyrodite $\mathrm{Li}_{6} \mathrm{PS}_{5} \mathrm{Br}$}

Ajay Gautam ${ }^{\mathrm{a}, \mathrm{b}}$, Marcel Sadowski ${ }^{\mathrm{c}}$, Nils Prinz ${ }^{\mathrm{d}}$, Henrik Eickhoff ${ }^{\mathrm{e}}$, Nicolò Minafra ${ }^{\mathrm{a}, \mathrm{b}}$, Michael Ghidiu ${ }^{\mathrm{a}, \mathrm{b}}$, Sean P. Culvere, ${ }^{\mathrm{a}, \mathrm{b}}$, Karsten Albe ${ }^{\mathrm{c}}$, Thomas F. Fässler ${ }^{\mathrm{e}}$, Mirjam Zobel ${ }^{\mathrm{d}}$, Wolfgang G. Zeier*a,b

${ }^{a}$ Institute of Physical Chemistry, Justus-Liebig-University Giessen, Heinrich-Buff-Ring 17, D35392 Giessen, Germany.

${ }^{b}$ Center for Materials Research (LaMa), Justus-Liebig-University Giessen, Heinrich-BuffRing 16, D-35392 Giessen, Germany.

${ }^{c}$ Department of Materials Science, Technische Universität Darmstadt, Otto-Berndt-Straße 3, D-64287 Darmstadt, Germany.

${ }^{d}$ Department of Chemistry, University of Bayreuth, Universitätsstr.30, D-95440 Bayreuth, Germany.

${ }^{e}$ Department of Chemistry, Technische Universität München, Lichtenbergstrasse 4, D-85747 Garching bei München, Germany. 


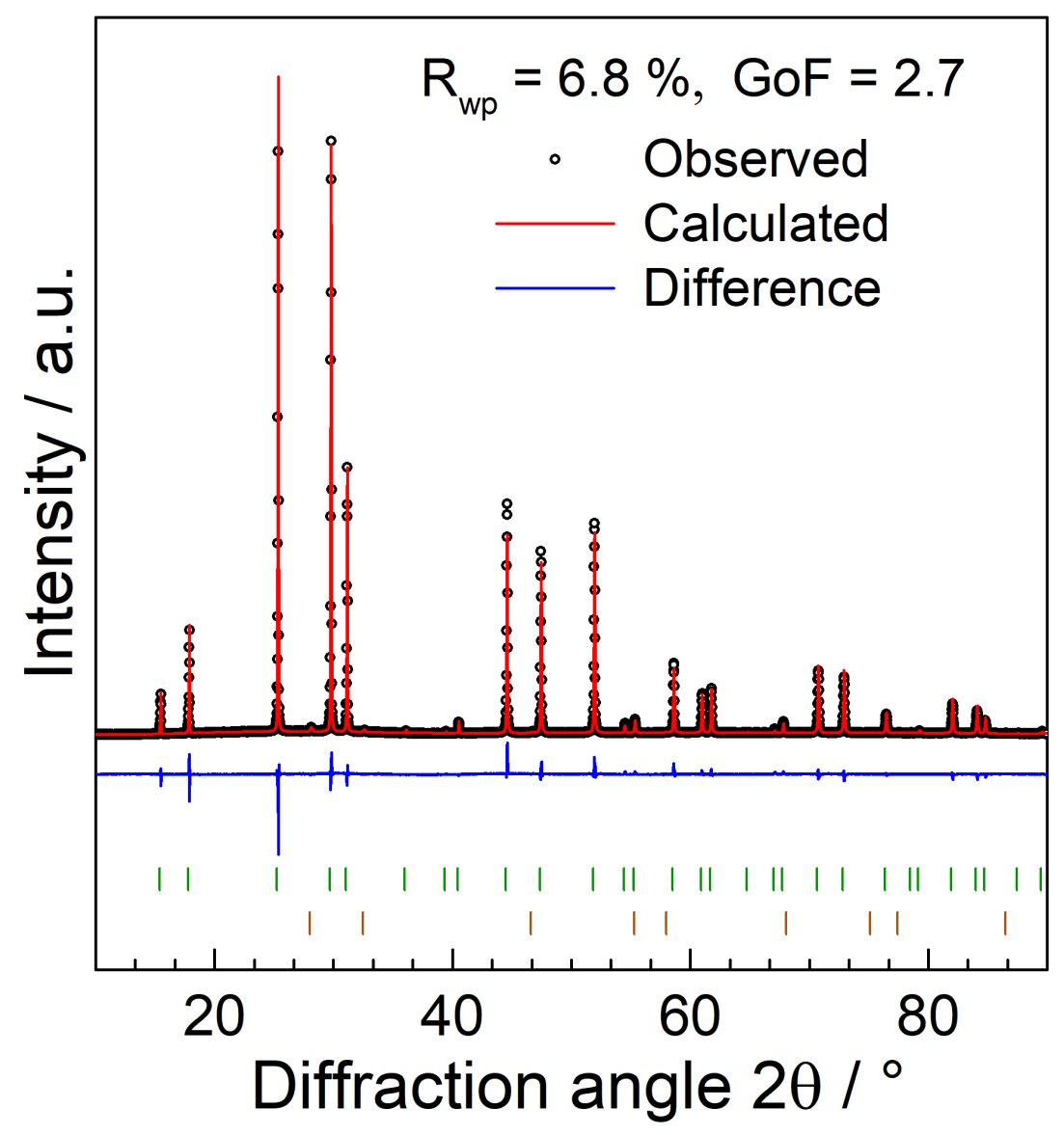

Figure S1: X-ray powder diffraction data for $\mathrm{Li}_{6} P \mathrm{~S}_{5} \mathrm{Br}$ after 5 min heating followed by quenching and corresponding Rietveld refinement. Experimental data are shown in black and the red line denotes the calculated pattern, while the difference profile is shown in blue. Calculated positions of the $\mathrm{Li}_{6} \mathrm{PS} \mathrm{S}_{5} \mathrm{Br}$ and $\mathrm{LiBr}$ Bragg reflections are shown as green and dark orange vertical ticks, respectively. 


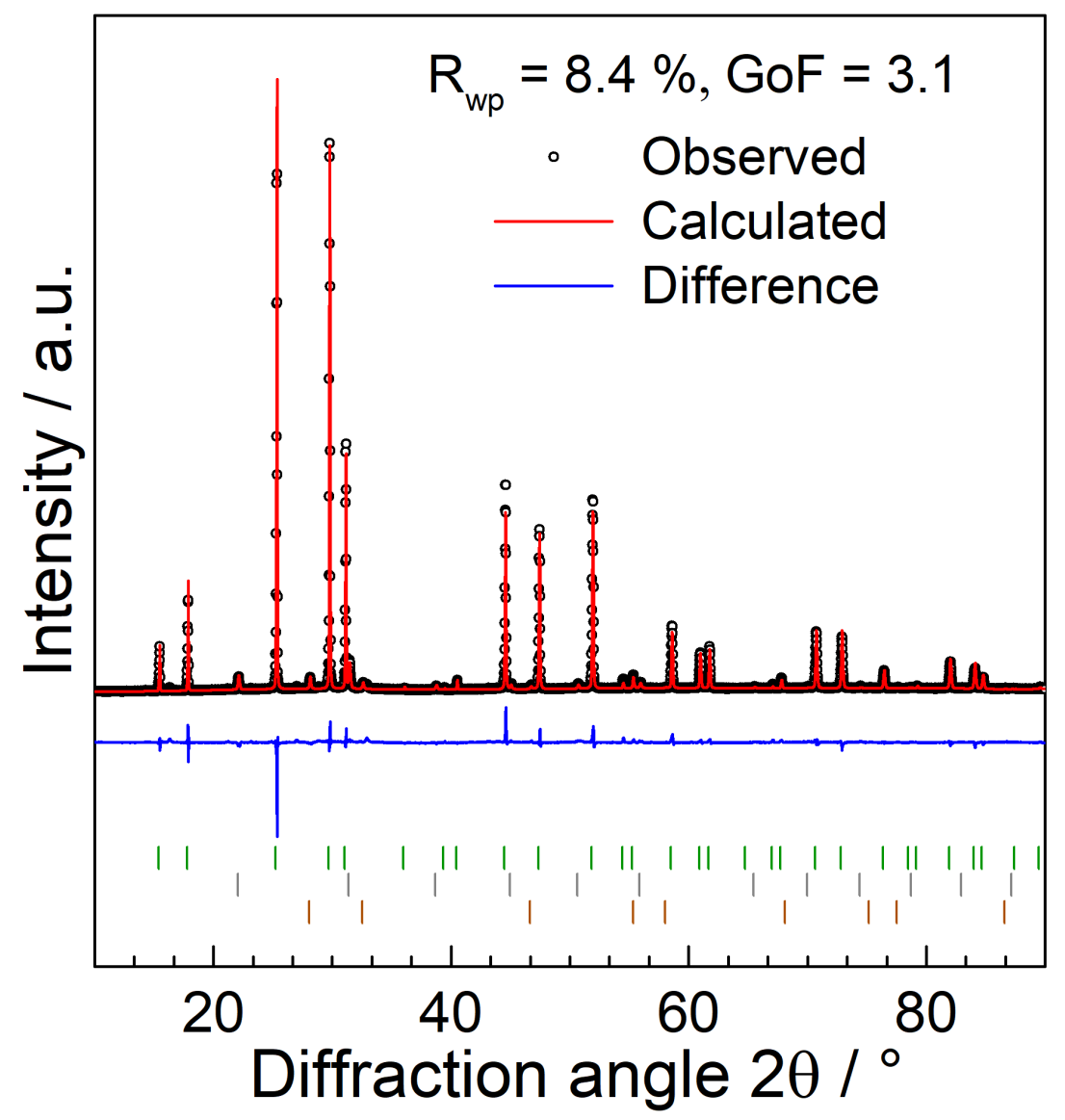

Figure S2: X-ray powder diffraction data for $\mathrm{Li}_{6} \mathrm{PS} \mathrm{S}_{5} \mathrm{Br}$ after 30 min heating followed by quenching and corresponding Rietveld refinement. Experimental data are shown in black and the red line denotes the calculated pattern, while the difference profile is shown in blue. Calculated positions of the $\mathrm{Li}_{6} \mathrm{PS}_{5} \mathrm{Br}, \mathrm{Li} i_{3} \mathrm{OBr}$ and $\mathrm{LiBr}$ Bragg reflections are shown as green, gray and dark orange vertical ticks, respectively. 


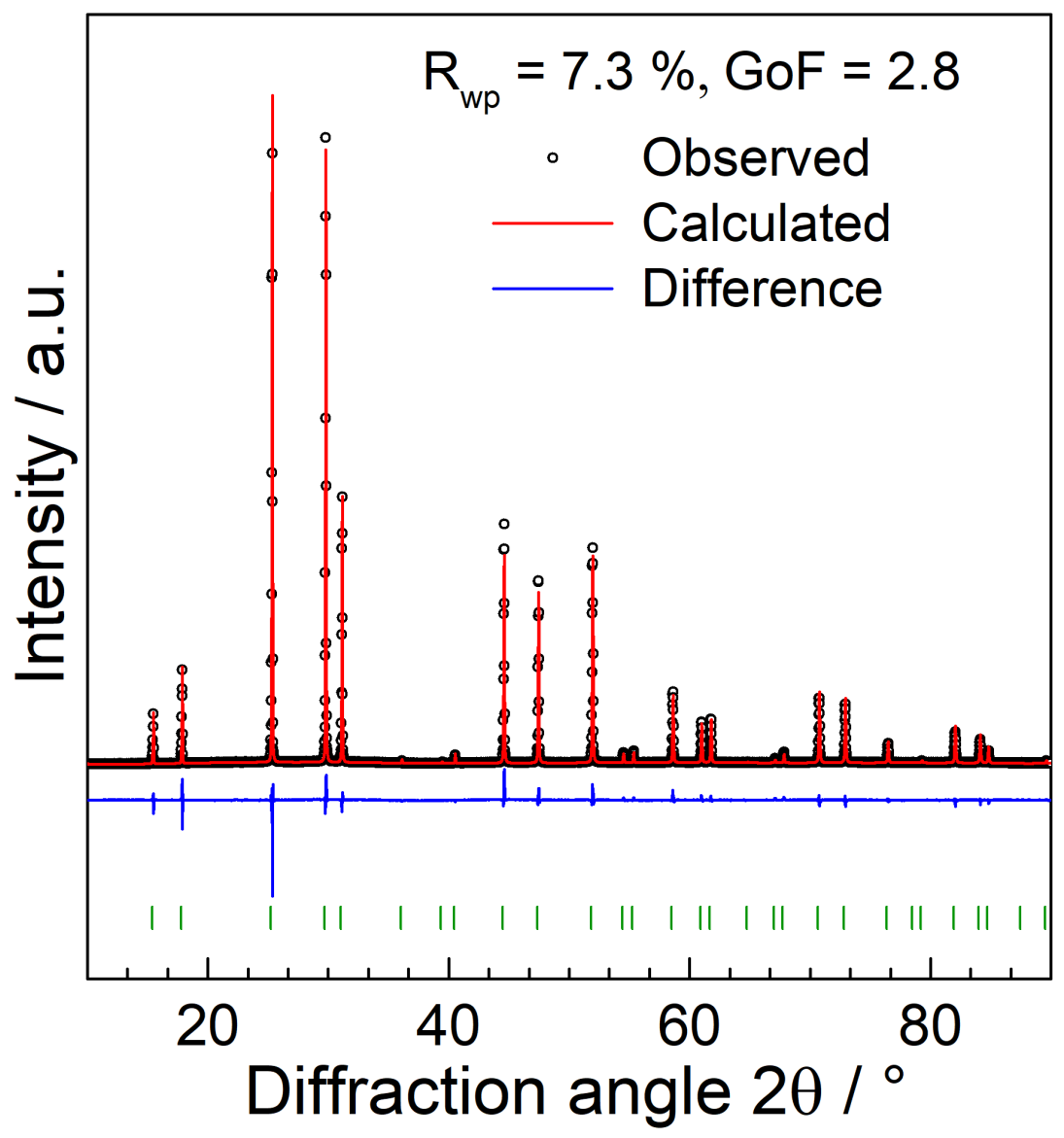

Figure S3: X-ray powder diffraction data for $\mathrm{Li}_{6} \mathrm{PS} \mathrm{S}_{5} \mathrm{Br}$ after 300 min heating followed by quenching and corresponding Rietveld refinement. Experimental data are shown in black and the red line denotes the calculated pattern, while the difference profile is shown in blue. Calculated positions of the $\mathrm{Li}_{6} \mathrm{PS} \mathrm{S}_{5} \mathrm{Br}$ Bragg reflections are shown as green vertical ticks, respectively. 


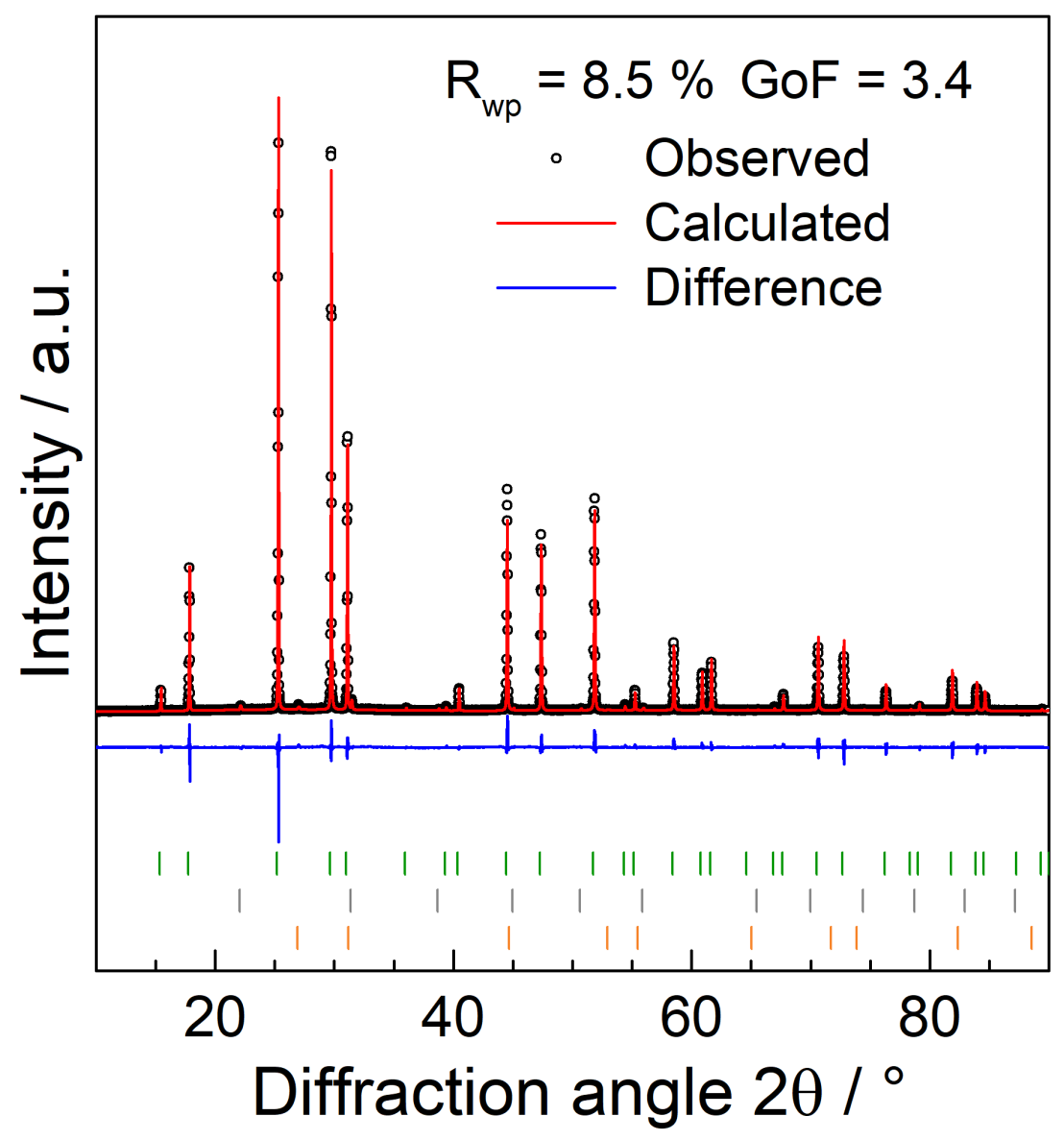

Figure S4: X-ray powder diffraction data for $\mathrm{Li}_{6} \mathrm{PS} \mathrm{S}_{5} \mathrm{Br}$ after 5 min heating followed by standard cooling and corresponding Rietveld refinement. Experimental data are shown in black and the red line denotes the calculated pattern, while the difference profile is shown in blue. Calculated positions of the $\mathrm{Li}_{6} \mathrm{PS} \mathrm{S}_{5} \mathrm{Br}, \mathrm{Li}_{2} \mathrm{~S}$ and $\mathrm{Li}_{3} \mathrm{OBr}$ Bragg reflections are shown as green, gray and orange vertical ticks, respectively. 


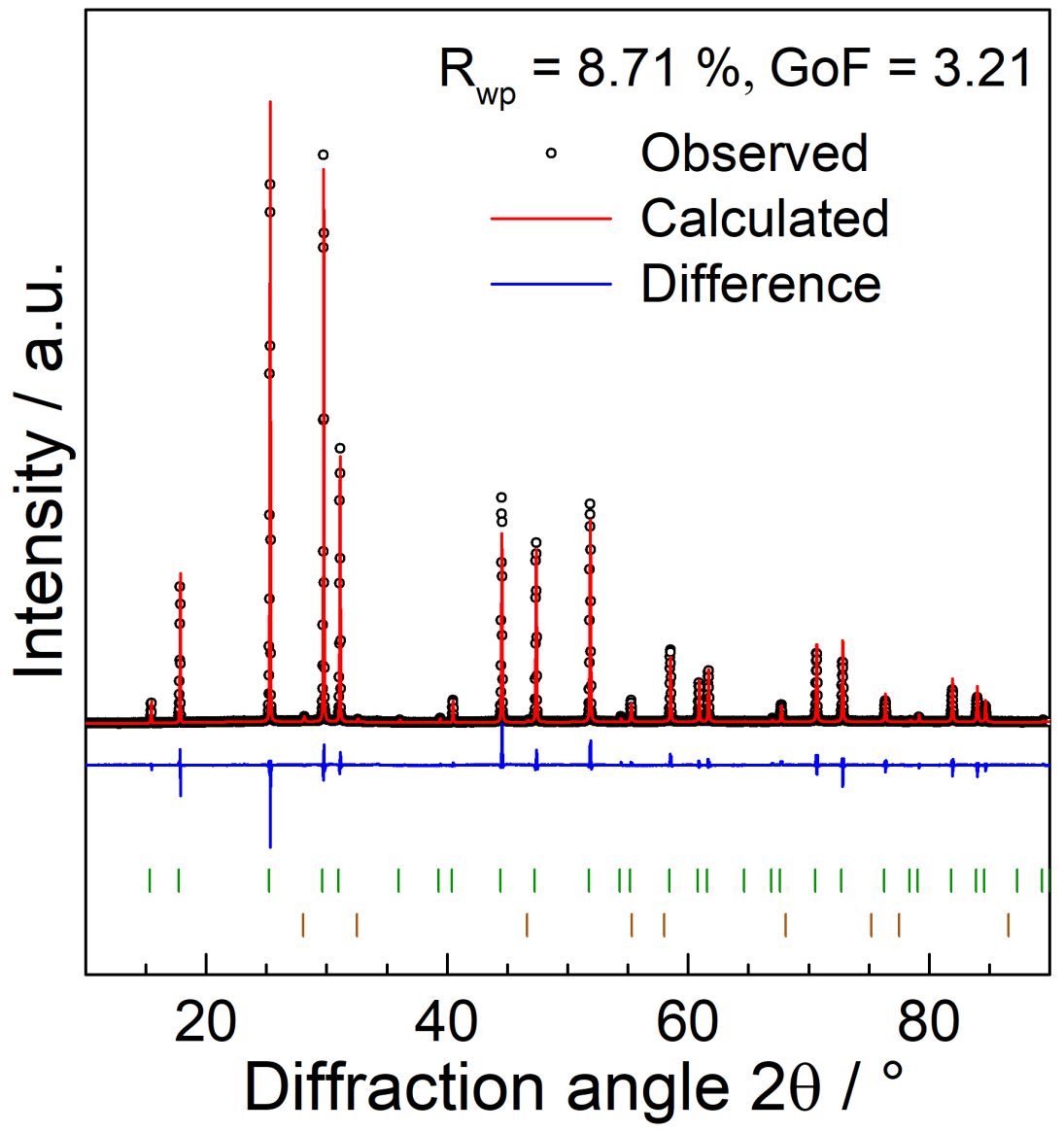

Figure S5: X-ray powder diffraction data for $\mathrm{Li}_{6} \mathrm{PS} \mathrm{S}_{5} \mathrm{Br}$ after $30 \mathrm{~min}$ heating followed by standard cooling and corresponding Rietveld refinement. Experimental data are shown in black and the red line denotes the calculated pattern, while the difference profile is shown in blue. Calculated positions of the $\mathrm{Li}_{6} \mathrm{PS}_{5} \mathrm{Br}$ and $\mathrm{LiBr}$ Bragg reflections are shown as green and dark orange vertical ticks, respectively. 


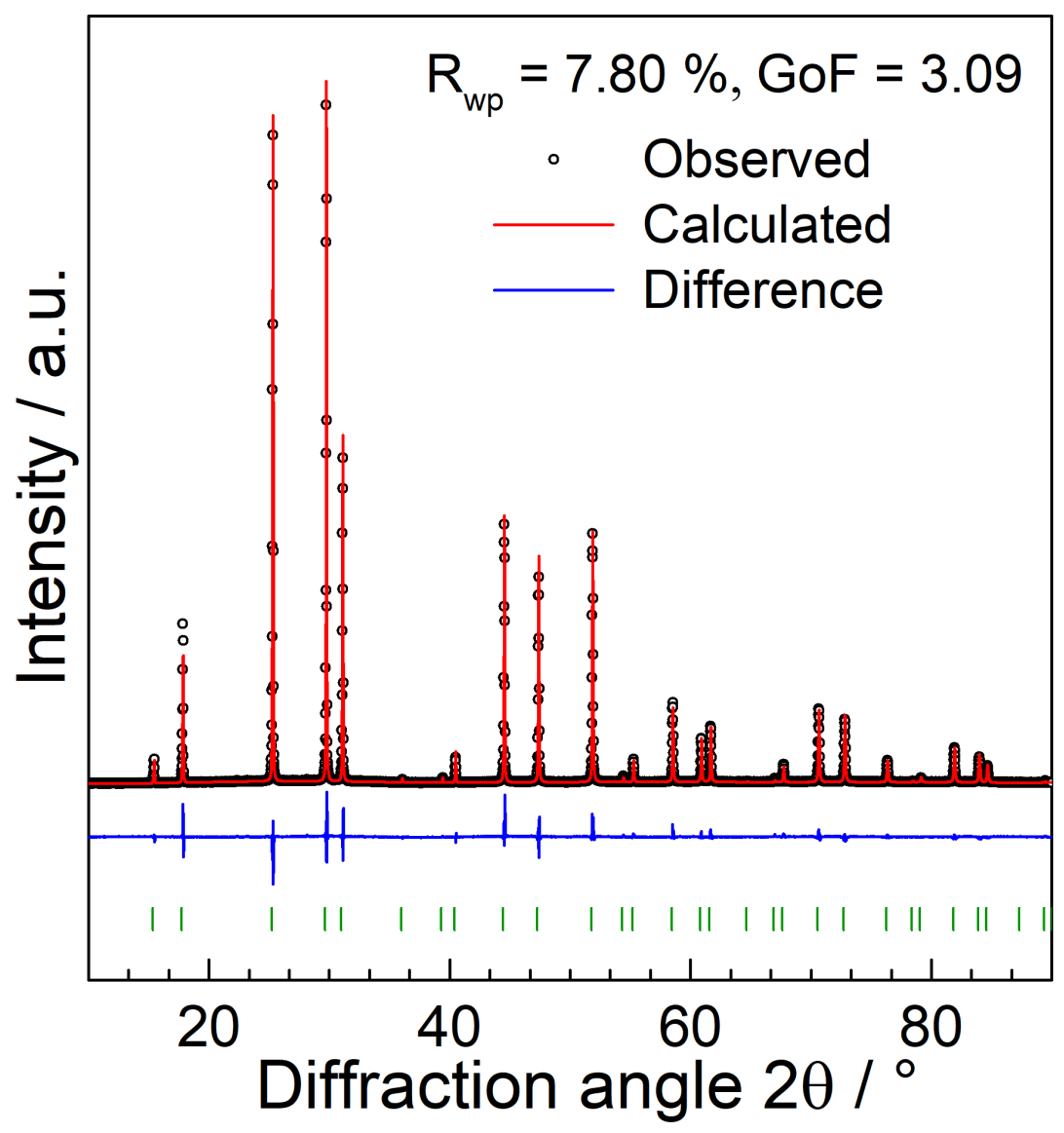

Figure S6: X-ray powder diffraction data for $\mathrm{Li}_{6} \mathrm{PS} \mathrm{S}_{5} \mathrm{Br}$ after 300 min heating followed by standard cooling and corresponding Rietveld refinement. Experimental data are shown in black and the red line denotes the calculated pattern, while the difference profile is shown in blue. Calculated positions of the $\mathrm{Li}_{6} P \mathrm{~S}_{5} \mathrm{Br}$ Bragg reflections are shown as green vertical ticks, respectively. 


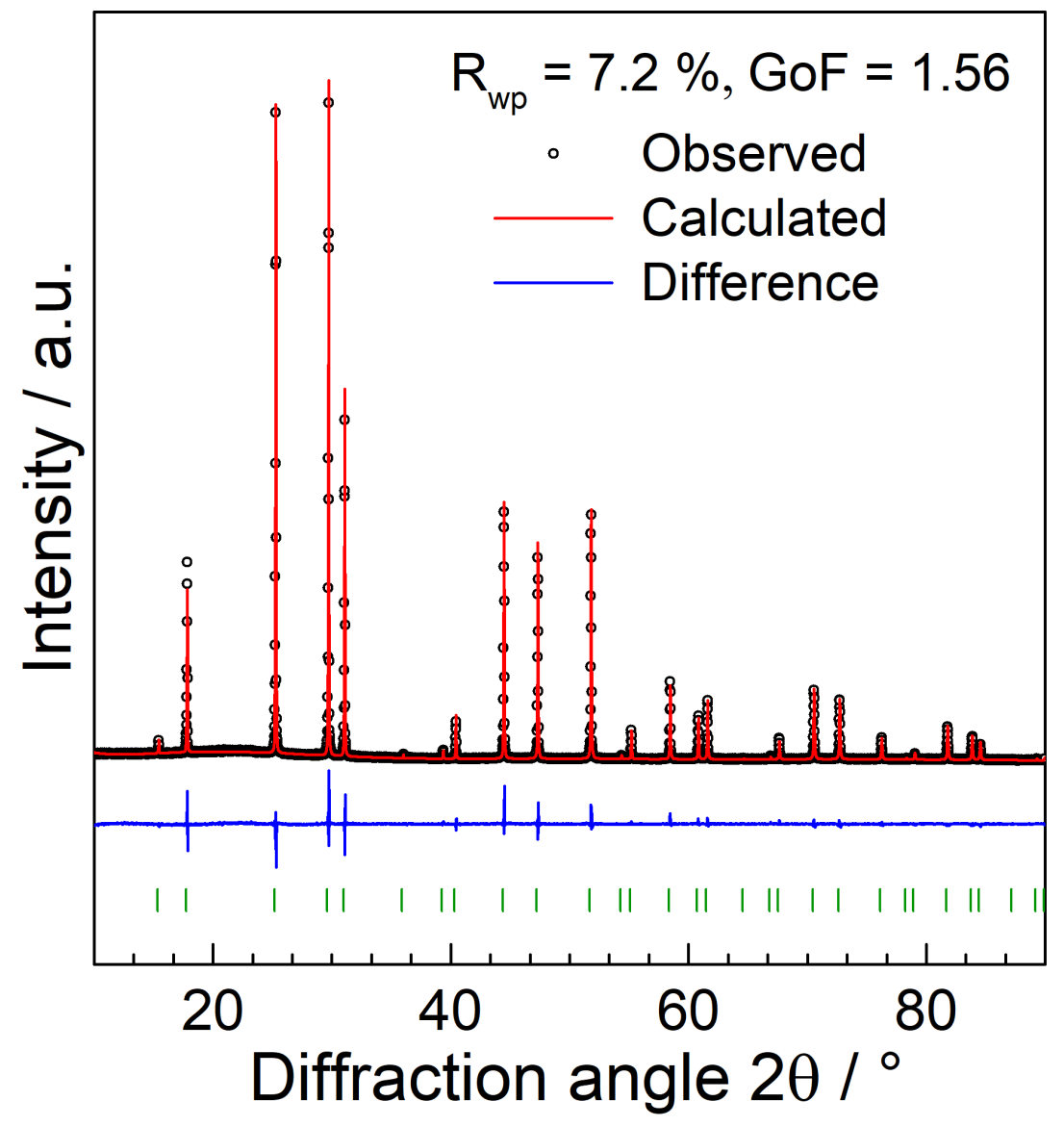

Figure S7: X-ray powder diffraction data for $L i_{6} P S_{5} B r$ after 30 min reaction at $550{ }^{\circ} \mathrm{C}$ then 5 -day cooling and corresponding Rietveld refinement. Experimental data are shown in black and the red line denotes the calculated pattern, while the difference profile is shown in blue. Calculated positions of the $\mathrm{Li}_{6} \mathrm{PS}_{5} \mathrm{Br}$ and LiBr Bragg reflections are shown as green and dark orange vertical ticks, respectively. 
Table S1. Crystallographic data of after 1 min of heating followed by quenching $\mathrm{Li}_{6} P S_{5} B r$ from Xray diffraction. Refined parameters are shown with uncertainty in brackets.

\begin{tabular}{|c|c|c|c|c|c|c|}
\hline \multicolumn{7}{|c|}{$\begin{array}{l}a=9.96696(3) \AA ; 0.73 \% \mathrm{LiBr} \\
\mathrm{R}_{\mathrm{wp}}=6.11 \% ; \mathrm{GoF}=2.47\end{array}$} \\
\hline Atom & $\begin{array}{l}\text { Wyckoff } \\
\text { Site }\end{array}$ & $x / a$ & $\mathrm{y} / b$ & $\mathrm{z} / \mathrm{c}$ & Occ & $\mathrm{B}_{\mathrm{eq}} / \AA^{2}$ \\
\hline Li1 & $48 h$ & 0.3071 & 0.0251 & 0.6929 & 0.4407 & 3 \\
\hline Li2 & $24 g$ & 0.25 & 0.017 & 0.75 & 0.1186 & 3 \\
\hline $\mathrm{Br} 1$ & $4 a$ & 1.0 & 1.0 & 1.0 & $0.635(2)$ & $1.25(4)$ \\
\hline $\mathrm{Br} 2$ & $4 d$ & 0.75 & 0.75 & 0.75 & $0.364(2)$ & $0.51(4)$ \\
\hline $\mathrm{P} 1$ & $4 b$ & 1.0 & 0.5 & 1.0 & 1.0 & $0.93(5)$ \\
\hline S1 & $4 d$ & 0.75 & 0.75 & 0.75 & $0.635(2)$ & $0.51(4)$ \\
\hline $\mathrm{S} 2$ & $16 e$ & $0.11954(8)$ & $-0.11954(8)$ & $0.61954(8)$ & 1.0 & $0.93(5)$ \\
\hline S3 & $4 a$ & 1.0 & 1.0 & 1.0 & $0.364(2)$ & $1.25(4)$ \\
\hline
\end{tabular}


Table S2. Crystallographic data after 5 min of heating followed by quenching $\mathrm{Li}_{6} \mathrm{PS} \mathrm{S}_{5} \mathrm{Br}$ from $\mathrm{X}$ ray diffraction. Refined parameters are shown with uncertainty in brackets.

\begin{tabular}{|c|c|c|c|c|c|c|}
\hline \multicolumn{7}{|c|}{$\begin{array}{l}a=9.96965(3) \AA ; 0.76 \% \mathrm{LiBr} \\
\mathrm{R}_{\mathrm{wp}}=6.8 \% ; \mathrm{GoF}=2.7\end{array}$} \\
\hline Atom & $\begin{array}{l}\text { Wyckoff } \\
\text { Site }\end{array}$ & $x / a$ & $\mathrm{y} / b$ & $\mathrm{z} / \mathrm{c}$ & Occ & $\mathrm{B}_{\mathrm{eq}} / \AA^{2}$ \\
\hline Li1 & $48 h$ & 0.3071 & 0.0251 & 0.6929 & 0.4407 & 3 \\
\hline Li2 & $24 g$ & 0.25 & 0.017 & 0.75 & 0.1186 & 3 \\
\hline $\mathrm{Br} 1$ & $4 a$ & 1.0 & 1.0 & 1.0 & $0.663(2)$ & $0.91(5)$ \\
\hline $\mathrm{Br} 2$ & $4 d$ & 0.75 & 0.75 & 0.75 & $0.337(2)$ & $0.21(4)$ \\
\hline $\mathrm{P} 1$ & $4 b$ & 1.0 & 0.5 & 1.0 & 1.0 & $0.50(4)$ \\
\hline S1 & $4 d$ & 0.75 & 0.75 & 0.75 & $0.663(2)$ & $0.21(4)$ \\
\hline S2 & $16 e$ & $0.11974(8)$ & $-0.11974(8)$ & $0.61974(8)$ & 1.0 & $0.50(4)$ \\
\hline S3 & $4 a$ & 1.0 & 1.0 & 1.0 & $0.337(2)$ & $0.91(5)$ \\
\hline
\end{tabular}


Table S3. Crystallographic data after 30 min of heating followed by quenching $\mathrm{Li}_{6} P \mathrm{PS}_{5} \mathrm{Br}$ from Xray diffraction. Refined parameters are shown with uncertainty in brackets.

\begin{tabular}{|c|c|c|c|c|c|c|}
\hline \multicolumn{7}{|c|}{$\begin{array}{l}a=9.97072(5) \AA ; 1.52 \% \mathrm{LiBr} ; 4.17 \% \mathrm{Li}_{3} \mathrm{OBr} \\
\mathrm{R}_{\mathrm{wp}}=8.4 \% ; \mathrm{GoF}=3.1\end{array}$} \\
\hline Atom & $\begin{array}{l}\text { Wyckoff } \\
\text { Site }\end{array}$ & $x / a$ & $\mathrm{y} / b$ & $\mathrm{z} / \mathrm{c}$ & Occ & $\mathrm{B}_{\mathrm{eq}} / \AA^{2}$ \\
\hline Li1 & $48 h$ & 0.3071 & 0.0251 & 0.6929 & 0.4407 & 3 \\
\hline Li2 & $24 g$ & 0.25 & 0.017 & 0.75 & 0.1186 & 3 \\
\hline $\mathrm{Br} 1$ & $4 a$ & 1.0 & 1.0 & 1.0 & $0.641(3)$ & $0.62(6)$ \\
\hline $\mathrm{Br} 2$ & $4 d$ & 0.75 & 0.75 & 0.75 & $0.358(3)$ & $0.14(5)$ \\
\hline $\mathrm{P} 1$ & $4 b$ & 1.0 & 0.5 & 1.0 & 1.0 & $0.06(3)$ \\
\hline S1 & $4 d$ & 0.75 & 0.75 & 0.75 & $0.641(3)$ & $0.14(5)$ \\
\hline S2 & $16 e$ & $0.1193(1)$ & $-0.1193(1)$ & $0.6193(1)$ & 1.0 & $0.06(3)$ \\
\hline S3 & $4 a$ & 1.0 & 1.0 & 1.0 & $0.358(3)$ & $0.62(6)$ \\
\hline
\end{tabular}


Table S4. Crystallographic data after 300 min of heating followed by quenching $\mathrm{Li}_{6} P S_{5} B r$ from Xray diffraction. Refined parameters are shown with uncertainty in brackets.

\begin{tabular}{|l|l|l|l|l|l|l|}
\hline \multicolumn{6}{|l|}{$\begin{array}{l}\text { a } 9.96866(3) \AA ; \\
\mathrm{R}_{\mathrm{wp}}=7.3 \% ; \mathrm{GoF}=2.8\end{array}$} \\
\hline Atom & $\begin{array}{l}\text { Wyckoff } \\
\text { Site }\end{array}$ & $x / a$ & $\mathrm{y} / b$ & $\mathrm{z} / c$ & Occ & \multicolumn{1}{l|}{ B $/ \AA^{2}$} \\
\hline Li1 & $48 h$ & 0.3071 & 0.0251 & 0.6929 & 0.4407 & 3 \\
\hline Li2 & $24 g$ & 0.25 & 0.017 & 0.75 & 0.1186 & 3 \\
\hline Br1 & $4 a$ & 1.0 & 1.0 & 1.0 & $0.624(2)$ & $0.99(5)$ \\
\hline Br2 & $4 d$ & 0.75 & 0.75 & 0.75 & $0.375(2)$ & $0.29(5)$ \\
\hline P1 & $4 b$ & 1.0 & 0.5 & 1.0 & 1.0 & $0.76(3)$ \\
\hline S1 & $4 d$ & 0.75 & 0.75 & 0.75 & $0.624(2)$ & $0.29(5)$ \\
\hline S2 & $16 e$ & $0.11976(8)$ & $-0.11976(8)$ & $0.61976(8)$ & 1.0 & $0.76(3)$ \\
\hline S3 & $4 a$ & 1.0 & 1.0 & 1.0 & $0.375(2)$ & $0.99(5)$ \\
\hline
\end{tabular}


Table S5. Crystallographic data after 1 min of heating followed by standard cooling $\mathrm{Li}_{6} \mathrm{PS} \mathrm{S}_{5} \mathrm{Br}$ from $X$-ray diffraction. Refined parameters are shown with uncertainty in brackets.

\begin{tabular}{|c|c|c|c|c|c|c|}
\hline \multicolumn{7}{|c|}{$\begin{array}{l}a=9.98112(3) \AA ; 0.67 \% \mathrm{LiBr} \\
\mathrm{R}_{\mathrm{wp}}=8.67 \% ; \mathrm{GoF}=3.22\end{array}$} \\
\hline Atom & $\begin{array}{l}\text { Wyckoff } \\
\text { Site }\end{array}$ & $x / a$ & $\mathrm{y} / b$ & $\mathrm{z} / c$ & Occ & $\mathrm{B}_{\mathrm{eq}} / \AA^{2}$ \\
\hline Li1 & $48 h$ & 0.3071 & 0.0251 & 0.6929 & 0.4407 & 3 \\
\hline Li2 & $24 g$ & 0.25 & 0.017 & 0.75 & 0.1186 & 3 \\
\hline $\mathrm{Br} 1$ & $4 a$ & 1.0 & 1.0 & 1.0 & $0.771(3)$ & $0.75(5)$ \\
\hline $\mathrm{Br} 2$ & $4 d$ & 0.75 & 0.75 & 0.75 & $0.228(3)$ & $0.32(6)$ \\
\hline P1 & $4 b$ & 1.0 & 0.5 & 1.0 & 1.0 & $0.22(3)$ \\
\hline S1 & $4 d$ & 0.75 & 0.75 & 0.75 & $0.771(3)$ & $0.32(6)$ \\
\hline $\mathrm{S} 2$ & $16 e$ & $0.11953(9)$ & $-0.11953(9)$ & $0.61953(9)$ & 1.0 & $0.22(3)$ \\
\hline S3 & $4 a$ & 1.0 & 1.0 & 1.0 & $0.228(3)$ & $0.75(5)$ \\
\hline
\end{tabular}


Table S6. Crystallographic data after 5 min of heating followed by standard cooling $\mathrm{Li}_{6} \mathrm{PS} \mathrm{S}_{5} \mathrm{Br}$ from X-ray diffraction. Refined parameters are shown with uncertainty in brackets.

\begin{tabular}{|l|l|l|l|l|l|l|}
\hline \multicolumn{6}{|l|}{$\begin{array}{l}\text { a } 9.98577(3) \AA ; 1.35 \% \mathrm{Li}_{2} \mathrm{~S} ; 1.05 \% \mathrm{Li}_{3} \mathrm{OBr} ; \\
\mathrm{R}_{\mathrm{wp}}=8.5 \% ; \mathrm{GoF}=3.4\end{array}$} \\
\hline Atom & $\begin{array}{l}\text { Wyckoff } \\
\text { Site }\end{array}$ & $x / a$ & $\mathrm{y} / b$ & $\mathrm{z} / c$ & Occ & Beq $\AA^{2}$ \\
\hline Li1 & $48 h$ & 0.3071 & 0.0251 & 0.6929 & 0.4407 & 3 \\
\hline Li2 & $24 g$ & 0.25 & 0.017 & 0.75 & 0.1186 & 3 \\
\hline Br1 & $4 a$ & 1.0 & 1.0 & 1.0 & $0.779(2)$ & $1.19(5)$ \\
\hline Br2 & $4 d$ & 0.75 & 0.75 & 0.75 & $0.220(2)$ & $0.76(6)$ \\
\hline P1 & $4 b$ & 1.0 & 0.5 & 1.0 & 1.0 & $0.55(3)$ \\
\hline S1 & $4 d$ & 0.75 & 0.75 & 0.75 & $0.779(2)$ & $0.76(6)$ \\
\hline S2 & $16 e$ & $0.11955(9)$ & $-0.11955(9)$ & $0.61955(9)$ & 1.0 & $0.55(3)$ \\
\hline S3 & $4 a$ & 1.0 & 1.0 & 1.0 & $0.220(2)$ & $1.19(5)$ \\
\hline
\end{tabular}


Table S7. Crystallographic data after 30 min of heating followed by standard cooling $\mathrm{Li}_{6} \mathrm{PS}_{5} \mathrm{Br}$ from X-ray diffraction. Refined parameters are shown with uncertainty in brackets.

\begin{tabular}{|c|c|c|c|c|c|c|}
\hline \multicolumn{7}{|c|}{$\begin{array}{l}a=9.98162(4) \AA ; 0.73 \% \mathrm{LiBr} \\
\mathrm{R}_{\mathrm{wp}}=8.7 \% ; \mathrm{GoF}=3.21\end{array}$} \\
\hline Atom & $\begin{array}{l}\text { Wyckoff } \\
\text { Site }\end{array}$ & $x / a$ & $\mathrm{y} / b$ & $\mathrm{z} / \mathrm{c}$ & Occ & $\mathrm{B}_{\mathrm{eq}} / \AA^{2}$ \\
\hline Li1 & $48 h$ & 0.3071 & 0.0251 & 0.6929 & 0.4407 & 3 \\
\hline Li2 & $24 g$ & 0.25 & 0.017 & 0.75 & 0.1186 & 3 \\
\hline $\mathrm{Br} 1$ & $4 a$ & 1.0 & 1.0 & 1.0 & $0.777(3)$ & $0.63(5)$ \\
\hline $\mathrm{Br} 2$ & $4 d$ & 0.75 & 0.75 & 0.75 & $0.222(3)$ & $0.23(7)$ \\
\hline P1 & $4 b$ & 1.0 & 0.5 & 1.0 & 1.0 & $0.45(4)$ \\
\hline S1 & $4 d$ & 0.75 & 0.75 & 0.75 & $0.777(3)$ & $0.23(7)$ \\
\hline $\mathrm{S} 2$ & $16 e$ & $0.1195(1)$ & $-0.1195(1)$ & $0.6195(1)$ & 1.0 & $0.45(4)$ \\
\hline S3 & $4 a$ & 1.0 & 1.0 & 1.0 & $0.222(3)$ & $0.63(5)$ \\
\hline
\end{tabular}


Table S8. Crystallographic data after 300 min of heating followed by standard cooling $\mathrm{Li}_{6} \mathrm{PS} \mathrm{S}_{5} \mathrm{Br}$ from X-ray diffraction. Refined parameters are shown with uncertainty in brackets.

\begin{tabular}{|c|c|c|c|c|c|c|}
\hline \multicolumn{7}{|c|}{$\begin{array}{l}a=9.98174(4) \AA \\
\mathrm{R}_{\mathrm{wp}}=7.8 \% ; \mathrm{GoF}=3.1\end{array}$} \\
\hline Atom & $\begin{array}{l}\text { Wyckoff } \\
\text { Site }\end{array}$ & $x / a$ & $\mathrm{y} / b$ & $\mathrm{z} / \mathrm{c}$ & Occ & $\mathrm{B}_{\mathrm{eq}} / \AA^{2}$ \\
\hline Li1 & $48 h$ & 0.3071 & 0.0251 & 0.6929 & 0.4407 & 3 \\
\hline Li2 & $24 g$ & 0.25 & 0.017 & 0.75 & 0.1186 & 3 \\
\hline $\mathrm{Br} 1$ & $4 a$ & 1.0 & 1.0 & 1.0 & $0.768(3)$ & $0.84(4)$ \\
\hline $\mathrm{Br} 2$ & $4 d$ & 0.75 & 0.75 & 0.75 & $0.231(3)$ & $0.48(6)$ \\
\hline P1 & $4 b$ & 1.0 & 0.5 & 1.0 & 1.0 & $0.38(3)$ \\
\hline $\mathrm{S} 1$ & $4 d$ & 0.75 & 0.75 & 0.75 & $0.768(3)$ & $0.48(6)$ \\
\hline S2 & $16 e$ & $0.11929(9)$ & $-0.11929(9)$ & $0.61929(9)$ & 1.0 & $0.38(3)$ \\
\hline S3 & $4 a$ & 1.0 & 1.0 & 1.0 & $0.231(3)$ & $0.84(4)$ \\
\hline
\end{tabular}


Table S9. Crystallographic data after 5-day cooling $\mathrm{Li}_{6} \mathrm{PS}_{5} \mathrm{Br}$ from X-ray diffraction. Refined parameters are shown with uncertainty in brackets.

\begin{tabular}{|c|c|c|c|c|c|c|}
\hline \multicolumn{7}{|c|}{$\begin{array}{l}a=9.99502(4) \AA ; \\
\mathrm{R}_{\mathrm{wp}}=7.2 \% ; \mathrm{GoF}=1.56\end{array}$} \\
\hline Atom & $\begin{array}{l}\text { Wyckoff } \\
\text { Site }\end{array}$ & $x / a$ & $\mathrm{y} / b$ & $\mathrm{z} / c$ & Occ & $\mathrm{B}_{\text {eq }} / \AA^{2}$ \\
\hline Li1 & $48 h$ & 0.3071 & 0.0251 & 0.6929 & 0.4407 & 3 \\
\hline Li2 & $24 g$ & 0.25 & 0.017 & 0.75 & 0.1186 & 3 \\
\hline $\mathrm{Br} 1$ & $4 a$ & 1.0 & 1.0 & 1.0 & $0.866(3)$ & $1.37(5)$ \\
\hline $\mathrm{Br} 2$ & $4 d$ & 0.75 & 0.75 & 0.75 & $0.133(3)$ & $1.07(7)$ \\
\hline $\mathrm{P} 1$ & $4 b$ & 1.0 & 0.5 & 1.0 & 1.0 & $0.85(4)$ \\
\hline $\mathrm{S} 1$ & $4 d$ & 0.75 & 0.75 & 0.75 & $0.866(3)$ & $1.07(7)$ \\
\hline $\mathrm{S} 2$ & $16 e$ & $0.11929(9)$ & $-0.11929(9)$ & $0.61929(9)$ & 1.0 & $0.85(4)$ \\
\hline S3 & $4 a$ & 1.0 & 1.0 & 1.0 & $0.133(3)$ & $1.37(5)$ \\
\hline
\end{tabular}



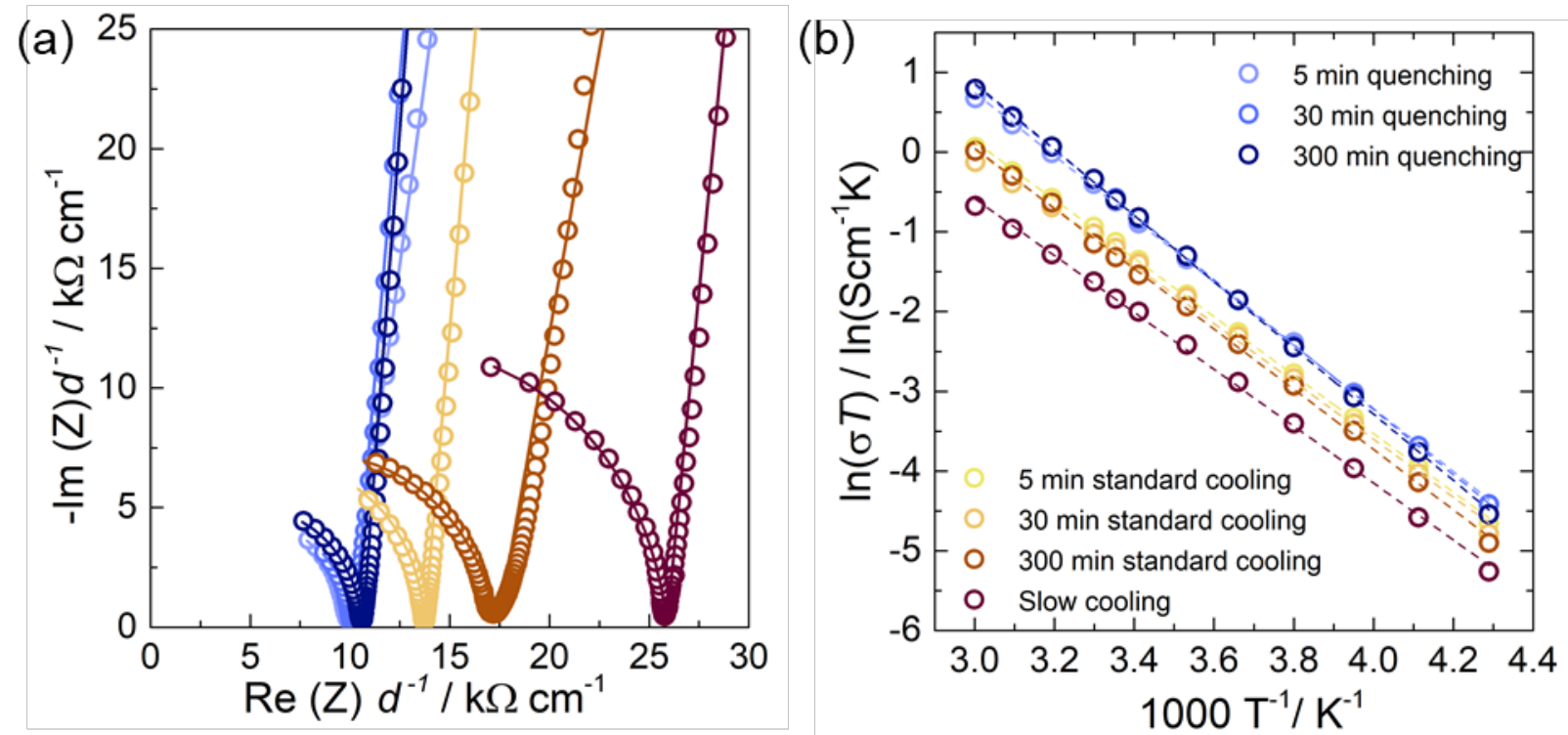

Figure S8: (a) A visual comparison of impedance spectra after using the quenching, standard cooling and slow cooling approach, measured at $253 \mathrm{~K}$. (b) Representative Arrhenius fits of the quenching, standard cooling and slow cooling obtained from impedance spectroscopy. 


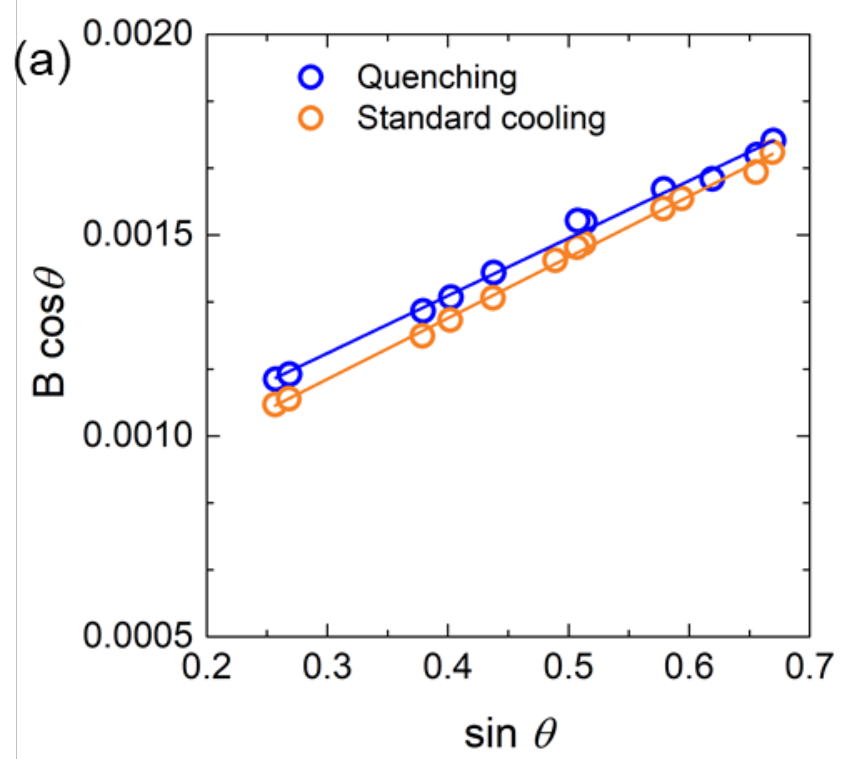

(b)

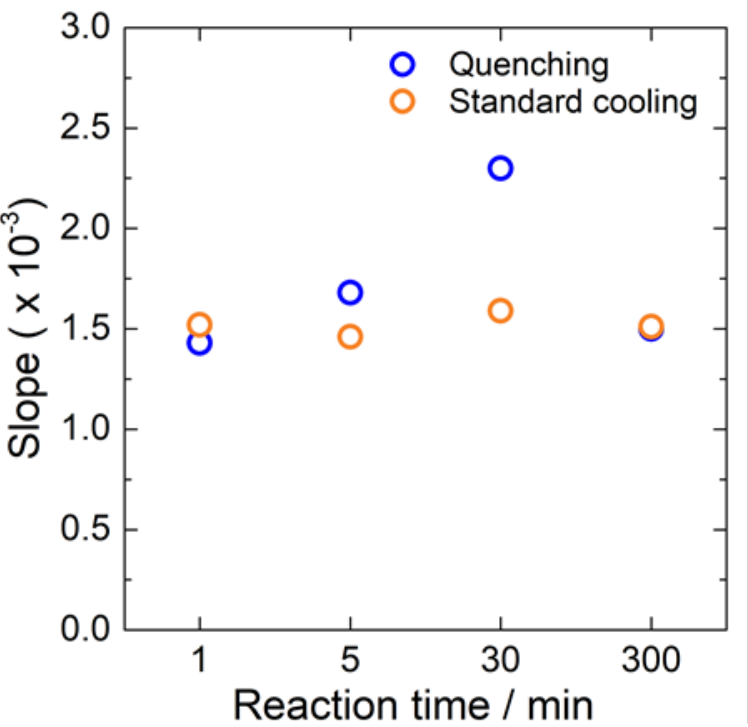

(c)

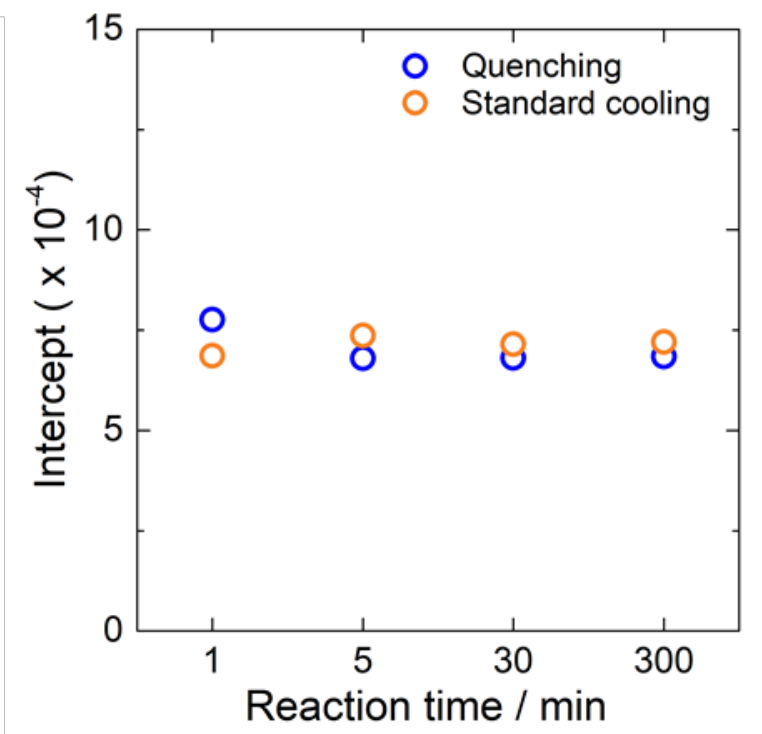

Figure S9: Williamson-Hall plot of the quenching and standard cooling obtained from X-ray diffraction. 


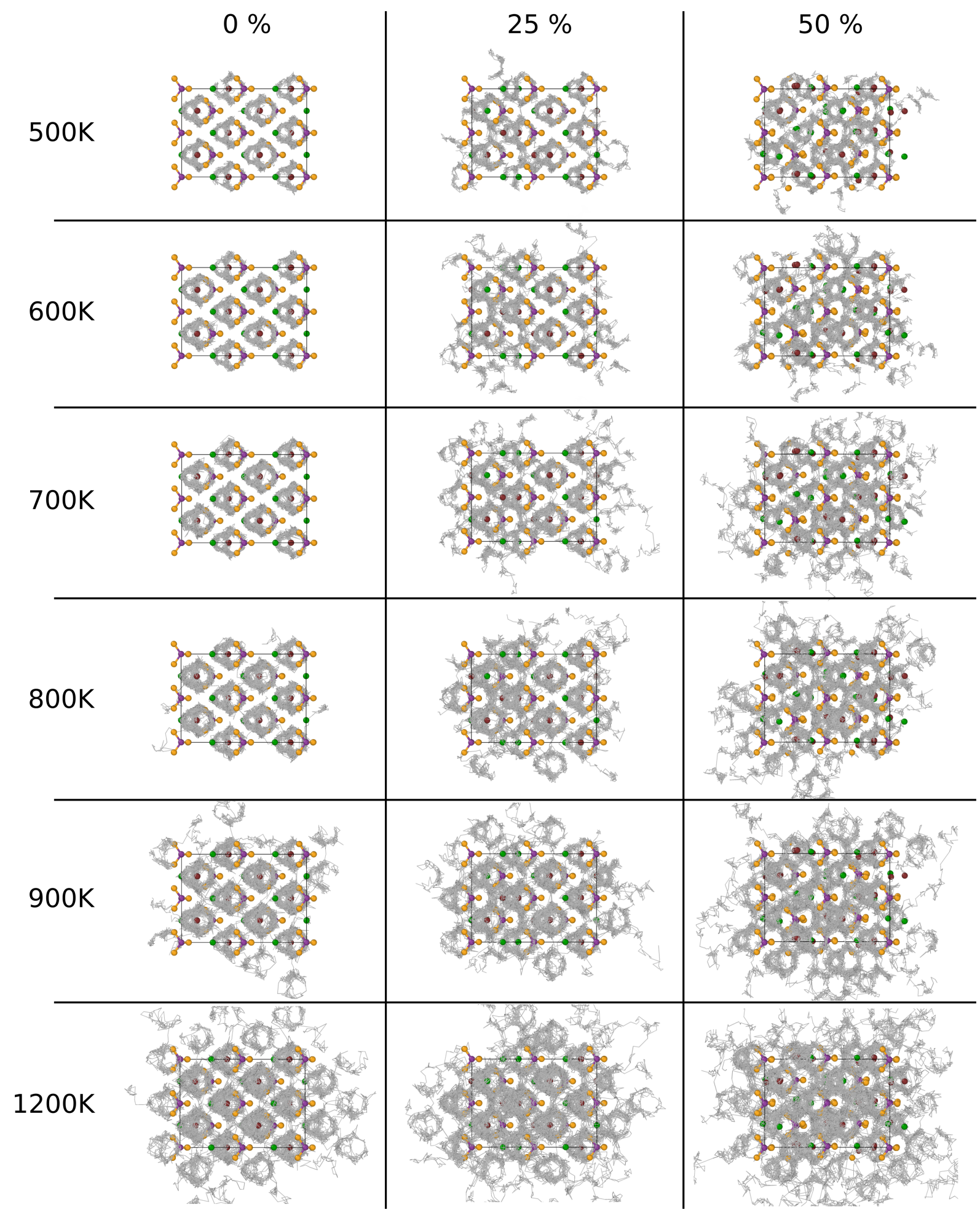

Figure S10: Ab-initio molecular dynamics calculated $\mathrm{Li}^{+}$trajectories of $\mathrm{Li}_{6} \mathrm{PS}_{5} \mathrm{Br}$ at $0 \%, 25 \%$ and $50 \%$ disorder between the $S$ and Br positions after 35 ps of simulation time. Clearly, longrange connecting jumps between the Li clusters occur at much lower temperatures for the disordered structure, compared to the fully ordered cell. 


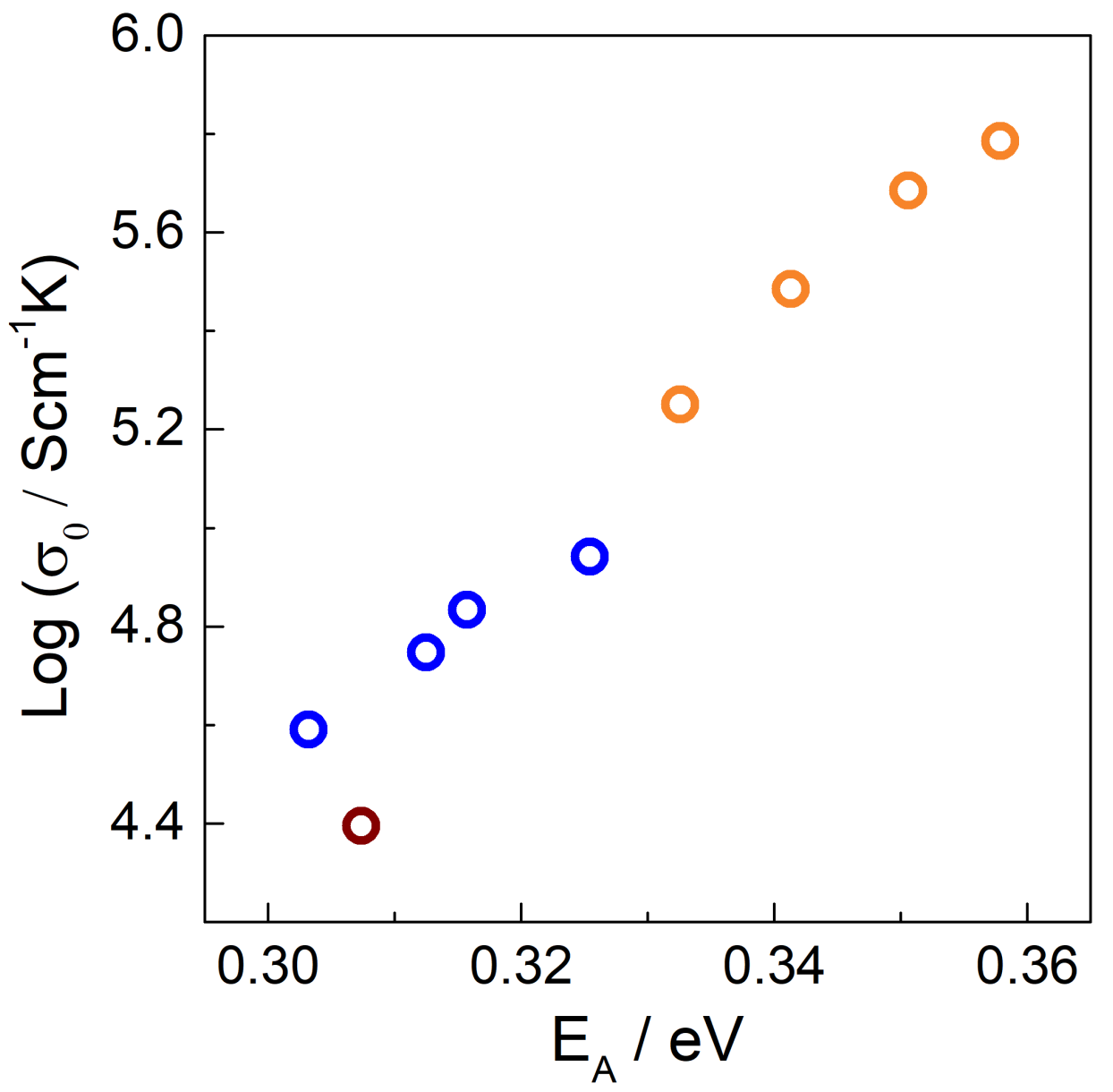

Figure S11: Meyer-Neldel plot of $\log \left(\sigma_{0}\right)$ vs. $E_{A}$. 
